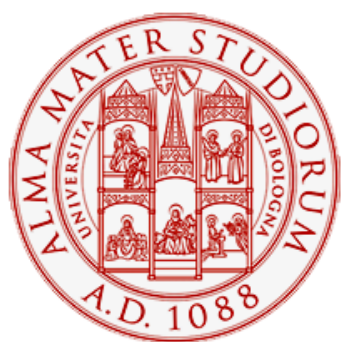

Alma Mater Studiorum - Università di Bologna DEPARTMENT OF ECONOMICS

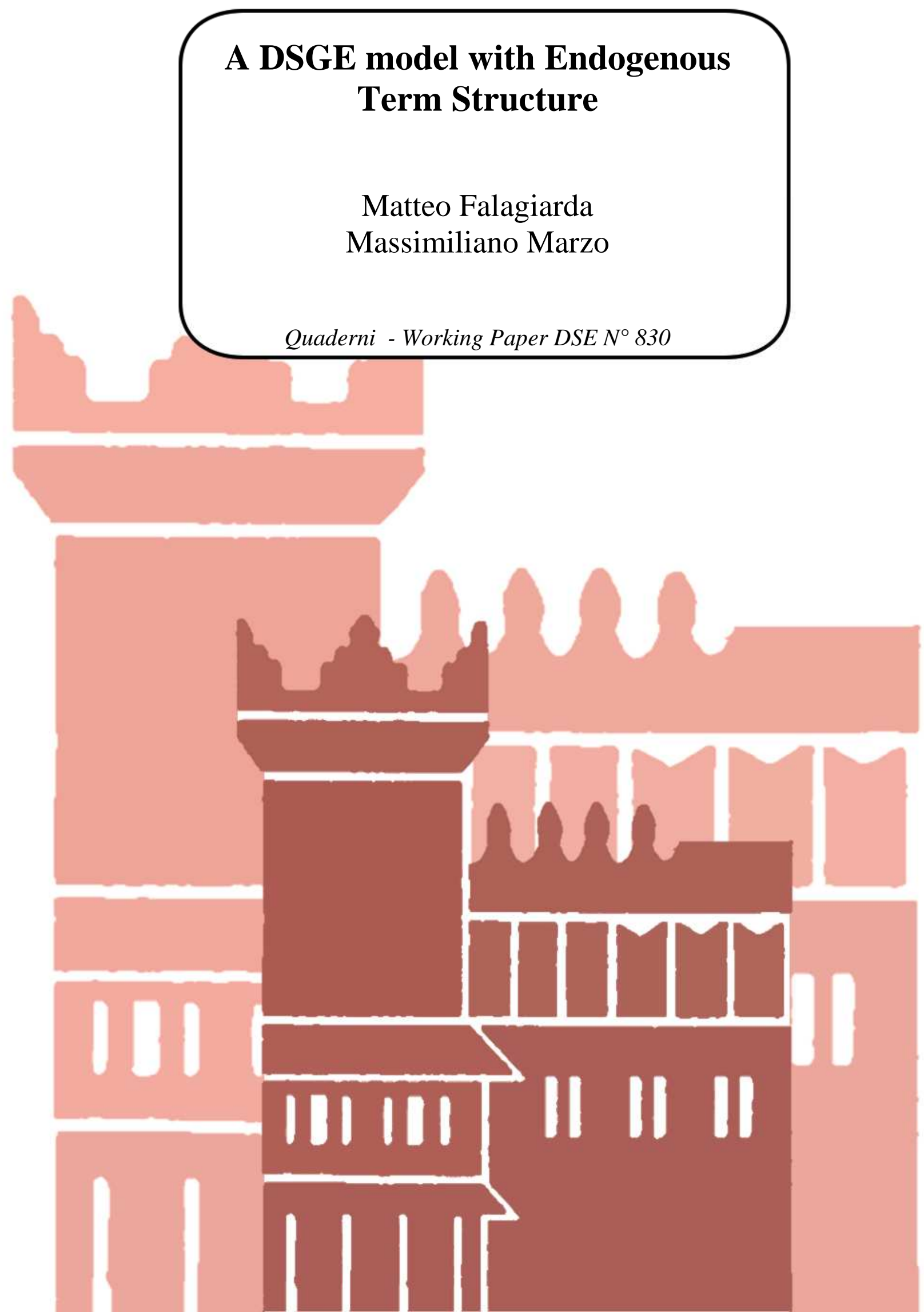




\title{
A DSGE model with Endogenous Term Structure
}

\author{
Matteo Falagiarda* $\quad$ Massimiliano $\mathrm{Marzo}^{\dagger}$ \\ June 5, 2012 \\ Do not circulate without authors' permission!
}

\begin{abstract}
In this paper, we propose a DSGE model with the term structure of interest rates drawing on the framework introduced by Andrés et al. (2004) and Marzo et al. (2008). In particular, we reproduce segmentation in financial markets by introducing bonds of different maturities and bond adjustment costs non-zero at the steady state, introducing a structural liquidity frictions among bonds with different maturities: agents are assumed to pay a cost whenever they trade bonds. As a result, the model is able to generate a non-zero demand for bonds of different maturities, which become imperfect substitutes, due to differential liquidity conditions. The main properties of the model are analysed through both simulation and estimation exercises. The importance of the results are twofold. On one hand, the calibrated model is able to replicate the stylized facts regarding the yield curve and the term premium in the US over the period 1987:3-2011:3, without compromising its ability to match macro dynamics. On the other hand, the estimation, besides providing an empirical support to the theoretical setting, highlights the potentialities of the model to analyze the term premium in a microfounded macro framework. The results match very closely the behavior of actual yields, reflecting the recent activity of the Fed on longer maturities bonds.
\end{abstract}

KEYWORDS: term structure, DSGE models

JEL Classification: C5, E32, E37, E43, E44

\footnotetext{
* Department of Economics, University of Bologna

${ }^{\dagger}$ Department of Economics, University of Bologna, 2, Piazza Scaravilli; Mail: massimiliano.marzo@unibo.it. Phone: +39-051-209 8019

${ }^{\ddagger}$ We have benefitted from conversations with Davide Raggi, Alessandro Saia and Paolo Zagaglia. We also thank participants at seminars at the Department of Economics of the University of Bologna, at the European University Institute of Florence, at the PhD Conference in Monetary and Financial Economics 2012 organized by the Centre for Global Finance of Bristol and at the 5th PhD Conference in Economics organized by the University of Athens for helpful comments. The usual disclaimer applies.
} 


\section{Introduction}

It is well known that one of the main limitations of standard DGSE models is their inability to generate sufficiently large and volatile term premia. ${ }^{1}$ Therefore, it has become an urgent task to better analyse the effects of real and nominal shocks on the term structure, and viceversa. Standard DSGE models, which represent the workhorse macro models of central banks and academic institutions, often lack a realistic and comprehensive representation of the financial sector. In particular, since all assets are taken as perfect substitutes, term premia are ignored, and the expectations hypothesis generally holds. Trying to incorporate in a coherent manner the term structure of interest rates into full-fledged DSGE models represents nowadays one of the most challenging research areas in macroeconomics.

In order to obtain richer models for policy advice it is crucial to bring term structure elements into general equilibrium frameworks. The yield curve is indeed very informative about expectations of future dynamics regarding macroeconomic variables (such as inflation and interest rates) and risk. More specifically, a complete understanding of term structure dynamics within DSGE models could be particularly helpful for the conduct of monetary policy. This issue has been gaining momentum in the last decade, as many central banks faced zero-bound interest rate challenges, or simply tried to react to unexpected or undesired changes of long term interest rates.

Recently, a macro-finance literature has been growing with the attempt to analyze how macro factors and the yield curve interact. Some works in this direction are due to Kozicki and Tinsley (2001), Ang and Piazzesi (2003), Hördahl et al. (2006), Evans and Marshall (2007), and Yang (2008), in which the macro structure is modelled as exogenous to the yield curve. ${ }^{2}$ Other studies (Dewachter and Lyrio, 2006; Diebold et al., 2006; Rudebusch and $\mathrm{Wu}, 2007,2008)$ are able to identify a bidirectional feedback between term structure factors and macro variables. The advantage of taking this joint perspective is twofold. On one hand, it is possible to observe how movements in the yield curve are affected by macroeconomic shocks. On the other hand, since the yield curve is a good predictor of future dynamics of the economy, these expectations contribute to the determination of current macroeconomic variables, although in a forward-looking setting. Thus, integrating term structure models with macro variables could substantially contribute to a better understanding of both financial and macroeconomic issues. Finally, reduced-form macro models have been developed by Wu (2006), Hördahl et al. (2008) and Bekaert et al. (2010). However, it is clear that this kind of frameworks, either linking macro variables to some latent-factor finance structures or using reduced-form macro models, cannot adequately address some important questions regarding the complex interactions between macro variables and asset prices.

Another stream of the literature has focused on how to integrate yield curve dynamics

\footnotetext{
${ }^{1}$ This has been called in the literature bond premium puzzle, is closely linked to the equity premium puzzle (Mehra and Prescott, 1985).

${ }^{2}$ This is the so-called dichotomous modeling approach (Rudebusch and Swanson, 2008). For an overview of this research area, see Diebold et al. (2005).
} 
into macro models with optimizing agents, such as DSGE models. Within these frameworks all variables obey a set of structural macro relations: for this reason, it is possible to give a more meaningful economic interpretation to the macro-finance connections. However, as explained by Rudebusch et al. (2007), standard DSGE models are not able to generate time-varying term premia. More specifically, the term premium is zero in firstorder approximations, and constant in second-order approximations.

In order to address these drawbacks, the literature has explored four approaches. The first one tries to capture the variability of the term premium by using higher-order approximations or global nonlinear methods (Ravenna and Seppälä, 2006; Rudebusch et al., 2007; Rudebusch and Swanson, 2008, 2009) combined with long-memory habit formation in consumption (as suggested by Campbell and Cochrane (1999)) and labor market frictions (Uhlig, 2007). These models generally find a larger and more volatile term premium than standard models, but still without matching the dynamics shown by data (i.e. movements of the term premium are too small), or at the cost of distorting the model's ability to fit other macroeconomic variables, as reported by Rudebusch and Swanson (2008).

The second approach introduces Epstein and Zin (1989) recursive preferences to differentiate the intertemporal elasticity of substitution from the inverse of the risk aversion coefficient. In this context, Rudebusch and Swanson (2009) within a DSGE framework drawing on an endowment economy developed by Piazzesi and Schneider (2006) with recursive preferences, are able to generate substantial volatility in the term premium. In particular, the model produces a reasonably large and volatile term premium matching also basic macroeconomic moments. However, their results come at the cost of an unrealistically high risk aversion parameter. Other contributions using Epstein-Zin preferences are due to van Binsbergen et al. (2010) and Hsu (2011).

A third type of DSGE models is characterized by the presence of heterogeneous agents (Guvenen, 2009; De Graeve et al., 2010; Hsu, 2011). For instance, the model by De Graeve et al. (2010) is able to capture the role of heterogeneous capital market participation across agents (shareholders, bondholders and workers), generating realistic term premia and reasonable dynamics for the intra- and intertemporal allocation decisions.

Other efforts to explain asset prices in macro models have been pursued by the socalled rare macroeconomic disasters literature, according to which asset returns volatility can be explained by incorporating disaster risk, in the form of a probability that a disaster will happen in the future (Gourio, 2009; Barro and Ursua, 2011).

Despite these recent substantial improvements Rudebusch (2010, p.40) himself admits that "the DSGE model financial sector remains far too rudimentary in terms of financial frictions and intermediation." More importantly, there are still theoretical uncertainties among economists about the appropriate model specification to analyse term premium within a DSGE framework (Rudebusch et al., 2007).

This paper adopts and extends the DSGE framework proposed by Marzo et al. (2008), which was one of the first studies endogenizing the yields of bonds with different maturities. In particular, our tractable model reproduces segmentation in financial markets by 
introducing bonds with different maturities and portfolio adjustment frictions. Transaction costs can be considered either as proxies for the liquidity of an asset, or simply costs associated to managing portfolios. Alternatively, the economic motivation for the inclusion of portfolio adjustment frictions may originate from the preferred habitat theory, whereby households have a preference for holding bonds of different maturity (Vayanos and Vila, 2009). These frictions generate a certain degree of stickiness in the timing of reallocation of bond holdings. As a result, the model is characterized by a non-zero demand for bonds of different maturities at each point in time, making assets imperfect substitutes. Our framework closely follows the message of Tobin $(1969,1982)$ about imperfect asset substitutability, whose portfolio approach has been first employed in a dynamic optimizing model by Andrés et al. (2004). With the model at hands, it is possible to analyse the dynamics of yield spreads and term premia in a general equilibrium setting. Moreover, the model features two feedback channels from the term structure to the macroeconomy, working, respectively, through money demand and the resource constraint.

The main operational advantage emerging from this setting is given by its ability to generate time-varying term premia, without recurring to higher order approximation of the simple first-order log-linearized solution.

The novelties of this paper with respect to Marzo et al. (2008)'s contribution are basically three. First of all, we allow for a secondary market for bond trading, as proposed by Ljungqvist and Sargent (2004). Second, open market operations by the central bank have been explicitly modelled, allowing the quantity of bonds of different maturities to move in response to shocks. Third, a deeper analysis of the term premium dynamics has been conducted.

The results highlighted in this paper are important along two dimensions, and differ substantially from the original model by Marzo et al. (2008). On the one hand, the calibrated model is able to replicate stunningly well the stylized facts regarding the yield curve in the US over the period 1987:3-2011:3. More specifically, the moments of the simulated data match very closely those of the US yield curve. Moreover, the IRFs show that after shocks term premia react consistently with what has been described in the literature. Finally, the model is able to generate a realistically high term premium while simultaneously matching the main macro dynamics, a fact that goes in the direction of solving the bond premium puzzle. The model is tested against data by using both calibration and bayesian estimation methods. In particular, the estimation procedure highlights the full potential of the model in analyzing the term premium within a microfounded macro framework: the estimated term premium generated by the model is very similar to that obtained by Kim and Wright (2005), both in terms of pattern and volatility.

The model presented in this paper points to further avenues for future research, like, for example, an analysis of the recent waves of Quantitative Easing policies carried out by central banks, and the study of the strategic asset allocation implications.

The paper is structured as follows. Section 2 presents the model. The results from the calibrated model are discussed in Section 3, while Section 4 is devoted to the results from 
the estimation. Section 5 concludes.

\section{The model}

\subsection{The household sector}

There is a continuum of identical and infinitely-lived households. Preferences are given by the infinite stream of utility given by:

$$
U_{t}=\sum_{t=0}^{\infty} \beta^{t} \nu_{t}^{p} u\left(C_{t}, \frac{M_{t}}{P_{t}}, L_{t}\right)
$$

where $\beta$ is the intertemporal discount factor. The instantaneous utility function $u\left(C_{t}, \frac{M_{t}}{P_{t}}, L_{t}\right)$ is given by:

$$
u\left(C_{t}, \frac{M_{t}}{P_{t}}, L_{t}\right)=\frac{\left(C_{t}-\gamma C_{t-1}\right)^{1-\frac{1}{\sigma}}}{1-\frac{1}{\sigma}}+\frac{1}{1-\chi}\left(\frac{M_{t}}{P_{t}}\right)^{1-\chi}-\frac{\Psi}{1+1 / \psi} L_{t}^{1+1 / \psi}
$$

In (1) $\nu_{t}^{p}$ is a preference shock that follows an $\operatorname{AR}(1)$ process:

$$
\log \nu_{t}^{p}=\phi_{P R} \log \nu_{t-1}^{p}+\varepsilon_{t}^{p}
$$

where $\varepsilon_{t}^{p}$ is an i.i.d. shock with zero mean and standard deviation $\sigma_{\nu p}$.

In this economy, each agent $i$ can choose the composition of a basket of differentiated final goods. The CES aggregator á la Dixit and Stiglitz (1977) is expressed by the following equation:

$$
C_{t}=\left[\int_{0}^{1} C_{t}(j)^{\frac{\theta_{t}-1}{\theta_{t}}} d j\right]^{\frac{\theta_{t}}{\theta_{t}-1}}
$$

where $C_{t}$ is an aggregate consumption index of all the differentiated final goods produced in this economy. There are $j$-th varieties of final goods $(j \in[0,1])$, and $\theta_{t}$ is a time-varying elasticity of substitution between different final goods varieties $\left(\theta_{t}>1\right) ; \sigma$ is the elasticity of intertemporal substitution, $\gamma$ measures the importance of consumption habits, $\chi$ is the elasticity of money demand, $\psi$ is the Frisch elasticity.

Each agent is subjected to the following budget constraint, which incorporates the secondary market for bond trading as in Ljungqvist and Sargent (2004):

$$
\begin{aligned}
& \frac{B_{t}}{P_{t} R_{t}}+\frac{B_{S, t}}{P_{t} R_{S, t}}\left(1+A C_{t}^{S}\right)+\frac{B_{M, t}}{P_{t} R_{M, t}}\left(1+A C_{t}^{M}\right)+\frac{B_{L, t}}{P_{t} R_{L, t}}\left(1+A C_{t}^{L}\right)+\frac{M_{t}}{P_{t}}\left(1+A C_{t}^{B}\right)+ \\
& +I_{t}\left(1+A C_{t}^{I}\right)=\frac{B_{t-1}}{P_{t}}+\frac{B_{S, t-1}}{P_{t} R_{t}}+\frac{B_{M, t-1}}{P_{t} R_{t}}+\frac{B_{L, t-1}}{P_{t} R_{t}}+\frac{M_{t-1}}{P_{t}}+\frac{W_{t}}{P_{t}} L_{t}+q_{t} K_{t}-C_{t}-T_{t}+\Omega_{t}
\end{aligned}
$$


Thus, agents allocate their wealth among money holding $M_{t}$, accumulation of capital $K_{t}$, which is rented to firms at the rental rate $q_{t}$, and holding of four types of zero-coupon bonds $\left(B_{t}, B_{S, t}, B_{M, t}, B_{L, t}\right)$, which are purchased by households at their nominal price. Agents receive rental income $q_{t} K_{t}$, where $K_{t}$ is capital, wage income $w_{t} L_{t}$, where $w_{t}$ is real wage, and a share of firms' profit $\Omega_{t}$. They also pay a real lump-sum tax $T_{t} ; I_{t}$ is investment, and $P_{t}$ is the aggregate price level. Firms face quadratic adjustment costs of investment as in $\operatorname{Kim}(2000)$ :

$$
A C_{t}^{I}=\frac{\phi_{K}}{2}\left(\frac{I_{t}}{K_{t}}\right)^{2}
$$

The law of motion of capital stock is expressed in the following standard way:

$$
K_{t+1}=I_{t}+(1-\delta) K_{t}
$$

where $\delta$ represents the depreciation rate of capital stock.

The different zero-coupon government bonds are defined as money-market bonds $B_{t}$, short-term bonds $B_{S, t}$, medium-term bonds $B_{M, t}$, and long-term bonds $B_{L, t}$, whose yields are given, respectively, by $R_{t}, R_{S, t}, R_{M, t}$, and $R_{L, t}$. The LHS of the budget constraint follows the usual formulation with bonds priced with their interest rates, since at time $t$, the return $R_{\imath, t}$ is known with certainty and is risk-free from the viewpoint of the agents. However, the RHS of (5) incorporates the secondary market for bond trading: bonds with different maturities are priced with the money-market rate. Even though these bonds represent sure claims for future consumption, they are subject to price risk prior to maturity. At time $t-1$, an agent who buys longer-maturity bonds and plans to sell them next period would be uncertain about the gains, since $R_{t}$ is not known at time $t-1$. As stressed by Ljungqvist and Sargent (2004), the price $R_{t}$ follows from a simple arbitrage argument, since, in period $t$, these bonds represent identical sure claims to consumption goods at the time of the end of the maturity as newly issued one-period bonds in period $t$.

As already mentioned, segmentation in financial markets is obtained by introducing portfolio adjustment frictions, representing impediments to the arbitrage behaviour of agents that would equalize asset returns. First of all, we propose bond-adjustment costs (Marzo et al., 2008), assuming that intertemporal bond trading is costly to each agent. Cost of bond adjustment are quadratic and are defined as follows:

$$
A C_{t}^{\imath}=\left[\frac{\phi_{\imath}}{2}\left(\frac{B_{\imath, t}}{B_{\imath, t-1}}\right)^{2}\right] Y_{t}
$$

where $\imath=S, M, L$. Costs defined by (8) are paid in terms of output, and are non-zero at the steady-state, generating a non-zero demand for bonds with different maturities in the long-run. The rationale behind the presence of transaction costs as in (8) is firstly 
related with the theory of preferred habitat, according to which agents have preferences over bond with different maturities (Vayanos and Vila, 2009). Under this view, transaction costs represent the inertial behaviour of the investor located at each maturity. Moreover, these costs are proxies for the shares of resources devoted to covering information costs, or the costs of managing bond portfolios. As stressed by Marzo et al. (2008), the magnitude of the adjustment costs $\phi_{\imath}$ at the steady-state is different across maturities, as they reflect different opportunity costs of bonds. In particular, as long as $R_{S}<R_{M}<R_{L}$ (an upward sloping yield curve), we have $\phi_{S}<\phi_{M}<\phi_{L}$.

The steady-state non-zero bond adjustment costs proposed in (8) represent another crucial innovative point of the present paper, in contrast with the existing literature, where portfolio reallocation among bonds are assumed to be zero (at steady state). This is what allow for differential yields among bonds, emerging from structural liquidity conditions characterizing the market of bonds having different maturities.

Moreover, we add money-bond transaction costs following Andrés et al. (2004), given by:

$$
A C_{t}^{B}=\left[\frac{v_{S}}{2}\left(\frac{M_{t}}{B_{S, t}} \kappa_{S}-1\right)^{2}+\frac{v_{M}}{2}\left(\frac{M_{t}}{B_{M, t}} \kappa_{M}-1\right)^{2}+\frac{v_{L}}{2}\left(\frac{M_{t}}{B_{L, t}} \kappa_{L}-1\right)^{2}\right] Y_{t}
$$

where $\kappa_{\imath}=b_{\imath} / m(\imath=S, M, L)$, i.e. the ratio between bond holdings and money in the steady-state. Thus, agents pay a cost whenever they shift the portfolio allocation between money and bonds with different maturities. Costs (9) are assumed to be zero at the steadystate ad they can be viewed as a rationalization of the liquidity premium, representing the attitude towards risk on behalf of representative agent. Longer is the maturity of a bond, the less liquid is considered the asset. These costs are set to be increasing with maturity $\left(v_{S}<v_{M}<v_{L}\right)$. Another intuition behind the presence of costs under (9) can be (Andrés et al., 2004): agents perceive longer-maturity assets as riskier, and therefore associated to a loss of liquidity in comparison with the same investment in shorter-term bonds. For this reason, as they purchase longer-term bonds, they hold additional money to compensate themselves for the loss of liquidity. Thus, agents self-impose a sort of "reserve requirements" on their longer-term investments.

\subsection{Optimality conditions}

Households maximize their lifetime utility stream (1), subjected to (2), (5), (6), (7), (8) and (9), together with an usual transversality conditions on all bonds.

The first order conditions with respect to consumption, labor, money, money-market bonds, short-term bonds, medium-term bonds, long-term bonds, capital and investment, are respectively given by: 


$$
\begin{aligned}
& \nu_{t}^{P}\left(C_{t}-\gamma C_{t-1}\right)^{-1 / \sigma}-\nu_{t+1}^{P} \beta \gamma E_{t}\left(C_{t+1}-\gamma C_{t}\right)^{-1 / \sigma}=\lambda_{t} \\
& \nu_{t}^{P} \Psi L_{t}^{1 / \psi}=\lambda_{t} \frac{W_{t}}{P_{t}} \\
& \nu_{t}^{P}\left(\frac{M_{t}}{P_{t}}\right)^{-\chi} \frac{1}{P_{t}}+\beta E_{t} \frac{\lambda_{t+1}}{P_{t+1}}=\frac{\lambda_{t}}{P_{t}}\left[1+A C_{t}^{B}\right]+ \\
& +\lambda_{t} \frac{M_{t}}{P_{t}}\left[v_{S} \kappa_{S}\left(\frac{M_{t}}{B_{S, t}} \kappa_{S}-1\right) \frac{Y_{t}}{B_{S, t}}+v_{M} \kappa_{M}\left(\frac{M_{t}}{B_{M, t}} \kappa_{M}-1\right) \frac{Y_{t}}{B_{M, t}}+v_{L} \kappa_{L}\left(\frac{M_{t}}{B_{L, t}} \kappa_{L}-1\right) \frac{Y_{t}}{B_{L, t}}\right] \\
& \beta E_{t} \frac{\lambda_{t+1}}{P_{t+1}}=\frac{\lambda_{t}}{P_{t} R_{t}} \\
& \beta E_{t} \frac{\lambda_{t+1}}{\pi_{t+1} R_{t+1}}+\beta \phi_{S} E_{t} \frac{\lambda_{t+1}}{R_{S . t+1}}\left(\frac{B_{S, t+1} / P_{t+1}}{B_{S, t} / P_{t}}\right)^{3} Y_{t+1}= \\
& =\frac{\lambda_{t}}{R_{S, t}}\left[1+\frac{3}{2} \phi_{S}\left(\frac{B_{S, t} / P_{t}}{B_{S, t-1} / P_{t-1}}\right)^{2} Y_{t}\right]-\lambda_{t}\left[\left(\frac{M_{t}}{B_{S, t}}\right)^{2} \kappa_{S} v_{S}\left(\frac{M_{t}}{B_{S, t}} \kappa_{S}-1\right) Y_{t}\right] \\
& \beta E_{t} \frac{\lambda_{t+1}}{\pi_{t+1} R_{t+1}}+\beta \phi_{M} E_{t} \frac{\lambda_{t+1}}{R_{M . t+1}}\left(\frac{B_{M, t+1} / P_{t+1}}{B_{M, t} / P_{t}}\right)^{3} Y_{t+1}= \\
& \frac{\lambda_{t}}{R_{M, t}}\left[1+\frac{3}{2} \phi_{S}\left(\frac{B_{M, t} / P_{t}}{B_{M, t-1} / P_{t-1}}\right)^{2} Y_{t}\right]-\lambda_{t}\left[\left(\frac{M_{t}}{B_{M, t}}\right)^{2} \kappa_{M} v_{M}\left(\frac{M_{t}}{B_{M, t}} \kappa_{M}-1\right) Y_{t}\right] \\
& \beta E_{t} \frac{\lambda_{t+1}}{\pi_{t+1} R_{t+1}}+\beta \phi_{L} E_{t} \frac{\lambda_{t+1}}{R_{L . t+1}}\left(\frac{B_{L, t+1} / P_{t+1}}{B_{L, t} / P_{t}}\right)^{3} Y_{t+1}= \\
& =\frac{\lambda_{t}}{R_{L, t}}\left[1+\frac{3}{2} \phi_{L}\left(\frac{B_{L, t} / P_{t}}{B_{L, t-1} / P_{t-1}}\right)^{2} Y_{t}\right]-\lambda_{t}\left[\left(\frac{M_{t}}{B_{L, t}}\right)^{2} \kappa_{L} v_{L}\left(\frac{M_{t}}{B_{L, t}} \kappa_{L}-1\right) Y_{t}\right] \\
& \beta(1-\delta) E_{t} \mu_{t+1}=\mu_{t}-\lambda_{t}\left(q_{t}+\phi_{K}\left(\frac{I_{t}}{K_{t}}\right)^{3}\right)
\end{aligned}
$$




$$
\beta E_{t} \mu_{t+1}=\lambda_{t}\left(1+\frac{3}{2} \phi_{K}\left(\frac{I_{t}}{K_{t}}\right)^{2}\right)
$$

where $\lambda_{t}$ and $\mu_{t}$ are the Lagrangian multipliers.

\section{$2.3 \quad$ Firms}

Each $j$-th firm produce and sell differentiated final goods in a monopolistically competitive market. The production function is a standard Cobb-Douglas with labor and capital:

$$
Y_{t}=A_{t} K_{t}^{\alpha} L_{t}^{1-\alpha}-\Phi
$$

where $\Phi$ is a fixed cost to ensure that profits are zero in the steady-state. $A_{t}$ is technology and follows an $\mathrm{AR}(1)$ process:

$$
\log A_{t}=\phi_{A} \log A_{t-1}+\varepsilon_{t}^{A}
$$

where $\varepsilon_{t}^{A}$ is an i.i.d. shock with zero mean and standard deviation $\sigma_{A}$.

Firms face quadratic price adjustment costs á la Rotemberg (1982), given by:

$$
A C_{t}^{P}=\frac{\phi_{P}}{2}\left(\frac{P_{t}(i)}{P_{t-1}(i)}-\pi\right)^{2} Y_{t}
$$

The demand function faced by each single firm $j$ is:

$$
Y_{t}(j)=\left[\frac{p_{t}(j)}{P_{t}}\right]^{-\theta_{t}} Y_{t} \Longrightarrow P_{t}(j)=\left[\frac{Y_{t}(j)}{Y_{t}}\right]^{-\frac{1}{\theta_{t}}} P_{t}
$$

Thus, the demand faced by each firm is directly related to the general output level of the economy, and negatively to the price of good $j$. The elasticity of substitution of demand $\theta_{t}$ is time-varying around a mean $\theta$ :

$$
\theta_{t}=\theta+\nu_{t}^{m}
$$

where $\nu_{t}^{m}$ is a shock to price markup that follows an autoregressive process:

$$
\log \nu_{t}^{m}=\phi_{M} \log \nu_{t-1}^{m}+\varepsilon_{t}^{m}
$$

With the presence of quadratic price adjustment costs highlighted under (21), the maximization problem becomes fully dynamic: each firm maximizes the expectation of 
the discounted sum of profit flows, given the information at time 0:

$$
\Pi_{0}(j)=E_{0}\left[\sum_{t=0}^{\infty} \rho_{t} P_{t} \Pi_{t}(j)\right]
$$

where $\rho$ is the firms' discount factor.

Following Kim (2000), the profit function for each firm $j$ is:

$$
P_{t} \Pi_{t}(j)=P_{t} P_{t}(j) Y_{t}(j)-P_{t} W_{t} L_{t}(j)-P_{t} q_{t} K_{t}(j)-P_{t} A C_{t}^{P}
$$

Assuming that each agent in the economy has access to a complete market for contingent claims, we have that the discount factor of households and firms are set to be equal, as in $\operatorname{Kim}(2000)$ :

$$
E_{t} \frac{\rho_{t+1}}{\rho_{t}}=E_{t} \beta \frac{\lambda_{t+1}}{\lambda_{t}}
$$

Therefore, the FOCs of the maximization problem with respect to labor and capital are given, respectively, by:

$$
\begin{aligned}
& \frac{W_{t}}{P_{t}}=(1-\alpha)\left(\frac{Y_{t}+\Phi}{L_{t}}\right)\left(1-\frac{1}{e_{t}^{Y}}\right) \\
& q_{t}=\alpha\left(\frac{Y_{t}+\Phi}{K_{t}}\right)\left(1-\frac{1}{e_{t}^{Y}}\right)
\end{aligned}
$$

where $e_{t}^{Y}$ is the output demand elasticity:

$$
\frac{1}{e_{t}^{Y}}=\frac{1}{\theta_{t}}\left\{1-\phi_{P}\left(\pi_{t}-\pi\right) \pi_{t}+\beta \phi_{P} E_{t}\left[\frac{\lambda_{t+1}}{\lambda_{t}}\left(\pi_{t+1}-\pi\right) \pi_{t+1}^{2} \frac{Y_{t+1}}{Y_{t}}\right]\right\}
$$

which measures the gross price markup over marginal cost. Given the above structure, it is immediate to check that the standard New-Keynesian aggregate supply curve obtains naturally after repeated substitution of the previous equations one into the other, after log-linearization around the non-stochastic steady state.

\subsection{The government sector}

The government constraint is:

$$
\frac{B_{t}}{P_{t} R_{t}}+\frac{B_{S, t}}{P_{t} R_{S, t}}+\frac{B_{M, t}}{P_{t} R_{M, t}}+\frac{B_{L, t}}{P_{t} R_{L, t}}+\frac{M_{t}}{P_{t}}=\frac{B_{t-1}}{P_{t}}+\frac{B_{S, t-1}}{P_{t} R_{t}}+\frac{B_{M, t-1}}{P_{t} R_{t}}+\frac{B_{L, t-1}}{P_{t} R_{t}}+\frac{M_{t-1}}{P_{t}}+G_{t}-T_{t}
$$

where $G_{t}$ is government spending, for which we assume to follow an $\mathrm{AR}(1)$ process:

$$
\log G_{t}=\phi_{G} \log G_{t-1}+\varepsilon_{t}^{G}
$$


where $\varepsilon_{t}^{G}$ is an i.i.d. shock with zero mean and standard deviation $\sigma_{G}$.

We introduce the following fiscal policy rule, where the total amount of tax collection is a function of the total government's liabilities, in order to prevent the emergence of inflation as a fiscal phenomenon, as suggested by (Leeper, 1991):

$T_{t}=\psi_{0}+\psi_{1}\left[\frac{b_{t-1}}{\pi_{t}}-\frac{b}{\pi}\right]+\psi_{2}\left[\frac{b_{S, t-1}}{R_{t} \pi_{t}}-\frac{b_{S}}{R \pi}\right]+\psi_{2}\left[\frac{b_{M, t-1}}{R_{t} \pi_{t}}-\frac{b_{M}}{R \pi}\right]+\psi_{2}\left[\frac{b_{L, t-1}}{R_{t} \pi_{t}}-\frac{b_{L}}{R \pi}\right]$

where $\psi_{0}$ is the steady-state level of $T_{t}$, and $\psi_{1}$ has been set to be equal for all bonds. Equation (33) tells us that the level of taxes react to deviations of the outstanding level of public debt from its steady-state level. In other words, taxes are not allowed to act independently from the stock of government liabilities outstanding in the economy.

Central Bank sets money-market rate $R_{t}$, according to the following Taylor (1993) rule:

$\log \left(\frac{R_{t}}{R}\right)=\alpha_{R} \log \left(\frac{R_{t-1}}{R}\right)+\left(1-\alpha_{R}\right)\left\{\log \left(\frac{\pi_{t}^{*}}{\pi}\right)+\alpha_{\pi}\left[\log \left(\frac{\pi_{t}}{\pi}\right)-\log \left(\frac{\pi_{t}^{*}}{\pi}\right)\right]+\alpha_{Y} \log \left(\frac{Y_{t}}{Y}\right)\right\}+\varepsilon_{t}^{R}$

where $\alpha_{R}, \alpha_{\pi}, \alpha_{Y}$ indicate the response of $R_{t}$ with respect to lagged $R_{t}$, inflation and output. The policy rate is determined by the deviation of inflation and output from steady-state with an interest rate smoothing component. Monetary policy shock $\varepsilon_{t}^{R}$ is an i.i.d. with zero mean and standard deviation $\sigma_{R} . \pi_{t}^{*}$ is a time-varying inflation target, as in Smets and Wouters (2003) and Zagaglia (2011):

$$
\log \left(\frac{\pi_{t}^{*}}{\pi}\right)=\phi_{\pi} \log \left(\frac{\pi_{t-1}^{*}}{\pi}\right)+\varepsilon_{t}^{\pi}
$$

Finally, instead of assuming a simple exogenous AR process for the supply of bonds, as in Marzo et al. (2008), let us suppose that central bank carries out open market operations (OMOs): whenever money demand increases (decreases), the central bank intervenes by buying (selling) government bonds of different maturities, and increasing (destroying) base money.

$$
\frac{M_{t} / P_{t}}{M_{t-1} / P_{t-1}}=\left(\frac{B_{\imath, t} / P_{t}}{B_{\imath, t-1} / P_{t-1}}\right)^{-\eta_{\imath}} \varepsilon_{t}^{B \imath}
$$

where $\eta_{\imath}$ is the coefficient of Open Market Operations indicates the elasticity of money growth supply with respect to changes in bond holdings for $\imath=S, M, L$. Coefficient $\eta_{\imath}$ indicates the extent by which changes in bond supply is reflected into money growth rate. According to (36), in order to respond to changes in money demand, the central bank varies the quantity of money supply by exchanging bonds, consistently with the policyrate objective. Thus, bond quantities are supply-driven. 
The resource constraint is:

$$
Y_{t}=C_{t}+G_{t}+I_{t}\left(1+A C_{t}^{I}\right)+\frac{b_{S, t}}{R_{S, t}}\left(A C_{t}^{S}\right)+\frac{b_{M, t}}{R_{M, t}}\left(A C_{t}^{M}\right)+\frac{b_{L, t}}{R_{L, t}}\left(A C_{t}^{L}\right)+m_{t}\left(A C_{t}^{B}\right)+A C_{t}^{P}
$$

From (37) total output is allocated to consumption, government spending, investment (comprehensive of capital adjustment costs), the price adjustment cost, and a component related to bond adjustment costs and money transaction costs.

\subsection{The pricing kernel}

It is now worth to show the main features underlying the bond pricing kernel emerging from this model, in order to understand why expectations hypothesis does not hold within this framework. Following Ljungqvist and Sargent (2004) and Marzo and Zagaglia (2011), and assuming the simplest case without adjustment or transaction costs, we can rewrite the FOCs of bond quantities as follows:

$$
\begin{aligned}
& \beta E_{t} \frac{\lambda_{t+1}}{\pi_{t+1}}=\frac{\lambda_{t}}{R_{t}} \\
& \beta E_{t} \frac{\lambda_{t+1}}{\pi_{t+1} R_{t+1}}=\frac{\lambda_{t}}{R_{i, t}}
\end{aligned}
$$

where $i=S, M, L$. The standard pricing kernel (or stochastic discount factor) is given by:

$$
M_{t+1}=R_{t}^{-1}=\beta E_{t} \frac{\lambda_{t+1}}{\lambda_{t} \pi_{t+1}}
$$

By using Eq.(40) and the law of iterated expectations, we obtain the pricing of of a twoperiods bond:

$$
R_{2, t}^{-1}=\beta^{2} E_{t} \frac{\lambda_{t+2}}{\lambda_{t} \pi_{t+1} \pi_{t+2}}
$$

We can generalize (41) to the $j$-th-period bond to get:

$$
R_{j, t}^{-1}=\beta^{j} E_{t} \frac{\lambda_{t+j}}{\lambda_{t+j-1}\left(\pi_{t+1} \ldots \pi_{t+j}\right)}
$$

The standard approach to term structure of interest rates implies that long-term interest rates are determined by expected future short-term rates. This is the so-called expectations hypothesis, whereby $R_{2, t}=R_{t} E_{t} R_{1, t+1}$. Let us check whether this hypothesis holds in our case. Eq.(39) can be rewritten as follows: ${ }^{3}$

$$
R_{i, t}^{-1}=\beta E_{t}\left[\frac{\lambda_{t+1}}{\lambda_{t} \pi_{t+1}}\right] E_{t} R_{t+1}^{-1}+\operatorname{Cov}_{t}\left[\beta \frac{\lambda_{t+1}}{\lambda_{t} \pi_{t+1}}, R_{t+1}^{-1}\right]
$$

\footnotetext{
${ }^{3}$ Remember that $\operatorname{Cov}(X, Y)=E[X Y]-E[X] E[Y]$.
} 
Using Eq.(38), we obtain:

$$
R_{i, t}^{-1}=R_{t}^{-1} E_{t} R_{t+1}^{-1}+\operatorname{Cov}_{t}\left[\beta \frac{\lambda_{t+1}}{\lambda_{t} \pi_{t+1}}, R_{t+1}^{-1}\right]
$$

where the covariance term represents the term premium. Eq.(44) implies that the Expectations Hypothesis, (EH, henceforth) holds only when utility is linear in consumption, i.e. when $\frac{\lambda_{t+1}}{\lambda_{t} \pi_{t+1}}=1$, leading the covariance term to disappear.

It is easy to check that in the present setting EH is not satisfied, since the utility is not linear in consumption. Moreover, there are also adjustment and transaction costs in the first order conditions of bonds of longer maturities (neglected in this analysis), that make the model characterized by a non-standard representation of the stochastic pricing equations. However, it is worth to note that what generates deviations from EH are determined by the presence of the budget constraint with secondary markets, allowing for bond trading before their maturities, while the portfolio adjustment frictions help to characterize the entire term structure, by inserting wedges among the various rate of returns.

\subsection{How money, bonds and yields interact}

It is evident that the model presents non-trivial dynamics for what concerns the relationships between money, yields and quantity of bonds. This paragraph aims to shed light on these mechanisms. The interrelationships among money, bonds and returns is depicted in the following diagram. Notice, in particular, that, differently from what has been assumed by Marzo et al. (2008), there is an effective bidirectional feedback between money and bond quantities, due to the presence of open market operations.

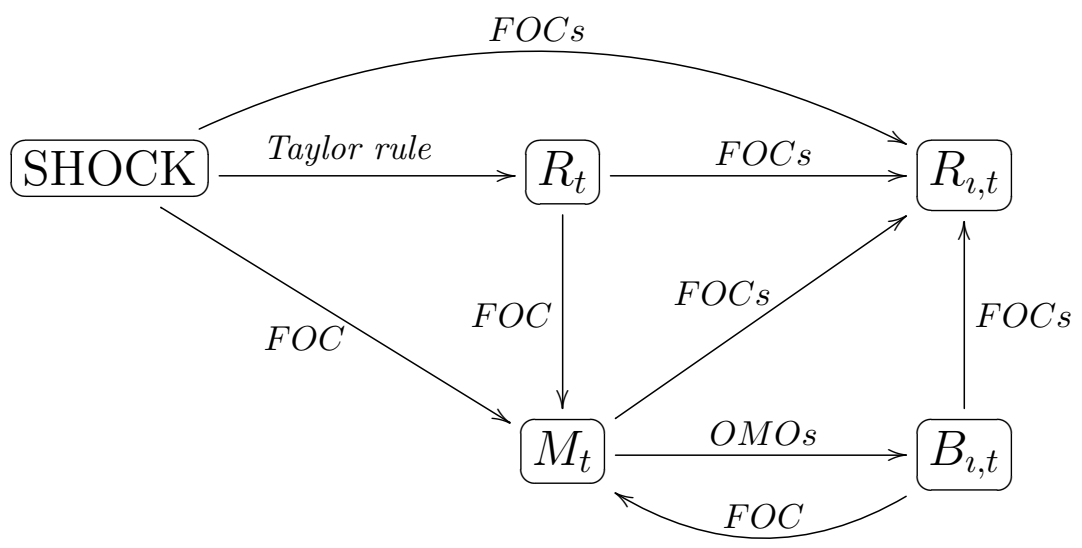

(Feedback channel)

Leaving aside the policy rate, determined by Taylor rule (34), and bond quantities of 
longer maturities, determined by open market operations (36), let us focus on the other variables of interest. Consider first a simplified log-linearized version of money demand equation:

$$
\tilde{m}_{t}=A_{1} E_{t} \tilde{c}_{t+1}-A_{2} \tilde{c}_{t}+A_{3} \tilde{c}_{t-1}-A_{4} \tilde{R}_{t}+A_{5} \tilde{b}_{S, t}+A_{6} \tilde{b}_{M, t}+A_{7} \tilde{b}_{L, t}
$$

where the $A$ coefficients are convolutions of structural parameters. Given the imperfect substitutability between money and bond holdings, money demand is positively affected by quantities of bonds at short, medium, and long maturities. This is due to the presence of the money-bond transaction costs. As previously stressed, households purchase longerterm assets and hold additional money to compensate for the potential loss of liquidity. Eq. (45) highlights one of the two feedback channels of the model from the term structure to the macroeconomy stressed by Marzo et al. (2008), namely a money demand channel. The other feedback channel works through the resource constraint, as it is possible to see by looking at Eq.(37). In the latter case, bond trasaction costs affect the spending decisions of agents.

It is worth to note that the present model lacks a channel through which aggregate demand depends directly on the prices of both short-term and longer-term maturity bonds, as in Harrison (2012). This extension will be the focus of a future work.

The log-linearized version of the first order conditions of bond holdings, from which yields of different maturities are derived, is given by:

$$
\begin{aligned}
& \tilde{R}_{\imath, t}=B_{1} \tilde{\lambda}_{t}-B_{2} E_{t} \tilde{\lambda}_{t+1}+B_{3} E_{t} \tilde{\pi}_{t+1}-B_{4} E_{t} \tilde{y}_{t+1}+B_{5} \tilde{y}_{t}+B_{6} E_{t} \tilde{R}_{\imath, t+1}+B_{7} E_{t} \tilde{R}_{t+1}- \\
& -\underbrace{v_{\imath} B_{4}\left[\tilde{m}_{t}-\tilde{b}_{\imath, t}\right]}_{\begin{array}{l}
\text { Imperfect asset } \\
\text { substitutability }
\end{array}}+\underbrace{\phi_{\imath} B_{5} \tilde{b}_{\imath, t}-\phi_{\imath} B_{6} \tilde{b}_{\imath, t-1}-\phi_{\imath} B_{7} E_{t} \tilde{b}_{\imath, t+1}}_{\text {Intertemporal stickiness }}
\end{aligned}
$$

where $\imath=S, M, L$, and the B coefficients are convolutions of structural parameters. Thus, yields of longer maturities are determined also by two components generated by portfolio adjustment frictions, which characterize respectively the degree of imperfect asset substitutability and the degree of intertemporal stickiness of bond trading. In particular, Eq.(46) reveals that the long-term rate depends positively on long-term bond supply, as desired, and positively on money supply, because of the imperfect asset substitutability. In other words, an increase in the relative supply of the more illiquid asset will bid up the spread between the more illiquid asset and the more liquid asset.

It is immediate to check that transaction and adjustment costs parameters generate impediments to the arbitrage activity which would equalize returns. At the same time, the presence of transaction costs determines the extent of the influence of relative assets holdings on long-term rate. From (46) when $\phi_{\imath}=0$, deviations from EH are smaller, and longer-term rates are not affected by changes in relative assets holdings. 


\section{Results from the calibrated version}

The model has been log-linearized around the non-shochastic steady-state, whose details are reported in Appendix A. We generate artificial time series of the variables, by simulating 1000 observations and discarding the first 500. The following paragraph will discuss how the calibration has been conducted. In what follows we report the calibration strategy.

\subsection{Calibration}

The benchmark model is calibrated to match US quarterly data over the period 1987:32011:3, the Greenspan-Bernanke era. Table 1 and Table 2 report, respectively, the steadystate values and the calibrated values of the core parameters. Some values have been chosen by following previous studies and are quite standard in the DSGE literature. In particular, the elasticity of substitution across goods $\theta$ is set to be equal to 6 (as SchmittGrohé and Uribe (2004)); habit formation parameter $\gamma$, is set to be equal to 0.7 (as in Smets and Wouters (2007)); the elasticity of intertemporal substitution $\sigma$, is 0.5 , which implies a coefficient of relative risk aversion of 2 ; the depreciation rate of capital $\delta$ is calibrated to be 0.025 (as in Christiano et al. (2005) and Altig et al. (2011)): this value implies an annual rate of depreciation on capital equal to 10 percent.

Capital share in production function $\alpha$ is set to 0.36 Christiano et al. (2005); Altig et al. (2011); parameter of price adjustment cost $\phi_{P}$, is set to be calibrated to 100 Ireland (2004). The elasticity of real money balances $\chi$, set equal to 7, as in Marzo et al. (2008); the Frisch elasticity $\psi$, set equal to 1 (Marzo et al. (2008)).

The parameters of the fiscal and monetary policy rules are mainly calibrated following Marzo et al. (2008), while the AR coefficients and the standard deviations of the shocks are set to $\phi_{A}=0.95, \phi_{G}=\phi_{M}=\phi_{P R}=\phi_{\pi}=\phi_{B L}=0.90, \sigma_{A}=0.01$, $\sigma_{B S}=\sigma_{B M}=\sigma_{B L}=0.0005, \sigma_{M}=\sigma_{P R}=\sigma_{R}=\sigma_{\pi}=0.005, \sigma_{G}=0.012$ (see, for example, Christiano and Eichenbaum, 1992; Kim, 2000; Andrés et al., 2004; Marzo et al., 2008; Altig et al., 2011; Zagaglia, 2011).

Transaction costs between money and bonds are considered as free parameters and are calibrated to match the empirical moments of the US yield curve, in the benchmark case. Their values are respectively set to be: $v_{S}=0.0030$ (which means $0.30 \%$ of income), $v_{M}=0.004$, and $v_{L}=0.0041$. In the next paragraphs a sensitivity analysis on these parameters will be performed to test robustness of the results conditional to benchmark calibrated values.

For what concerns parameters $\eta_{S}, \eta_{M}$ and $\eta_{L}$ we consider several options, by testing the model with free values and with some parameters obtained from the conduct of open market operations in the US, and from data. We rely therefore on various issues of 
the Domestic Open Market Operations Report prepared by the New York Fed, and we set these parameters to $2.5,2.5$, and 7 , respectively. These values are indicative of the period prior to the financial crisis, during which holdings of government securities were skewed towards the shorter end of the maturity spectrum. In fact, it is well known that, from 2008, purchases of government securities were instead weighted towards longer term maturities. However, in the next section we will carry out some sensitivity analysis on these parameters, in order to show the mechanisms behind the Open Market Operations (OMO) formulation within this framework.

Steady-state value of some variables is obtained from the data, or following previous studies. Output is normalized to 1 . The consumption-output ratio has been set to 0.57, and the taxes-output ratio to 0.1972 (Marzo et al., 2008). The ratio of market to nonmarket activities is set equal to 0.3. The ratio of total debt on GDP is calibrated to 0.45 (Schmitt-Grohé and Uribe, 2004; Marzo et al., 2008). The ratio of debt at different maturities to total debt is obtained from the OECD Database, using US series from 1995 to 2010 and calculating the average over this period. The steady-state values of the yields have been calculated from the Federal Reserve Economic Data.

Finally, values of remaining parameters and variables are computed using steady-state solutions, as shown in the Appendix.

\subsection{The benchmark model}

\subsubsection{Moments of the simulated variables}

It is useful to start by illustrating some stylized fact of US term structure in recent years. Table 3 summarizes the main moments of US term structure over the period 1987:32011:3. We report standard deviations of yield spread and of yields with four maturities (the Federal Funds Rate, 3 months, 1 year, 5 years, and 10 years), the correlation between the output gap (computed as a percentage deviation of real GDP from potential), and yield spreads. The statistics have been computed using Federal Reserve Economic Data. As expected, rates of shorter maturity are generally more volatile than those of longer maturities. Moreover, the yield spread is countercyclical.

Table 4 displays the analogous statistics of the simulated data generated by the model using the benchmark calibration. ${ }^{4}$ Standard deviations of various maturities yields are extremely close to actual data, reported in Table 3. The same can be said for the volatility of yield spreads. The only exception is for the policy rate, whose standard deviation is

\footnotetext{
${ }^{4}$ The yield spread is simply computed by taking the difference between the long-term rate and the money-market rate. The term premium $\xi_{t}$ is defined as follows:

$$
R_{L, t}=\frac{1}{N} \sum_{j=0}^{N-1} E_{t} R_{S, t+j}+\xi_{t}
$$

Thus, the term premium is the deviation of the long-term yield $R_{L, t}$ from the level consistent with the expectations hypothesis. Since we assume that the short-rate $R_{S, t}$ is the 3-month yield and the long-term rate $R_{L, t}$ is the 10 -year rate, we have $N=40$.
} 
very low because we did not include any specific investment technology (like transaction costs) for bonds paying a return equal to the policy rate, as explained by Ljungqvist and Sargent (2004, p.377).

Furthermore, the contemporaneous correlation of the spread with the output gap is negative, as found in actual data over the considered sample. We also report the standard deviation of the generated term premium, as well as its contemporaneous correlation with the output gap. The term premium is found to be countercyclical: this negative relationship in real data is documented by Rudebusch et al. (2007). More importantly, it is worth to note that comparatively to standard DSGE models using higher order approximations, ${ }^{5}$ the standard deviation of the term premium emerging from our model is much higher and very close to the empirical ones.

Thus, it seems that the model in its benchmark calibrated version is able to generate moments that match stunningly well the U.S. term structure features over the GreenspanBernanke period, and, at the same time, to reproduce a sufficiently and realistically large term premium.

\subsubsection{IRF functions}

Impulse response functions with respect to one standard deviation innovations to the three main shocks (technology, monetary policy and government spending) are shown in Figures 1-3. ${ }^{6}$ A positive productivity shocks (Figure 1 ) leads to a decreasing response of inflation, which, in turn, causes a reduction in the monetary policy rate. Moreover, the responses of the remaining yield rates are negative, due to the decreasing response in money-market rate. After shock money demand increases, while the term premium falls as response to the shock, reaching a minimum of around $0.13 \%$. The direction of the response of the term premium is consistent with what has been showed by Rudebusch et al. (2007) in a standard business cycle model with a third-order approximation. However, our model is able to generate a response substantially higher than that reported in Rudebusch et al. (2007). Finally, main macro variables dynamics are perfectly consistent with the patterns derived from a standard DSGE model.

Figure 2 plots the the impulse responses to a contractionary monetary policy shock, which, not surprisingly, triggers a negative response of inflation and output. The increase in the policy rate drives money demand down, and yields of different maturities hike: the model does not display any liquidity puzzle. Moreover, on impact after the shock the term premium displays an increase: this is again consistent with Rudebusch et al. (2007). Previous considerations about the size of the response of the term premium and the dynamics of the macro variables apply for results displayed in Figure 2 as well.

\footnotetext{
${ }^{5}$ The standard deviation of the term premium estimated by Kim and Wright (2005) is around 0.752 (computed over the period 1990:4-2011:3).

${ }^{6}$ The IRFs concerning the other shocks, and not reported here, are available upon request.
} 
A government spending shock (Figure 3) leads to an increase in output and inflation, crowding out consumption. As a result, money demand falls, driven by an increase in the policy rate. In line with Rudebusch et al. (2007), the term premium experiences an increase on impact.

Summing up, we have shown that the baseline version of the model is capable to match the main stylized fact about the US term structure without distorting the dynamics of the main macro variables. To our knowledge, this is the first DSGE model that, by endogeneizing the term structure, is able to achieve this goal. In particular, while the direction of the response of the term premium to the shocks is consistent with what previously found in the DSGE literature, its magnitude is much higher. Next sections are devoted to sensitivity analysis, where we will show how the term structure dynamics vary after changing key model parameters.

\subsection{Sensitivity analysis}

The goal of the next two paragraphs is to gain intuition about some of the mechanisms at work in the model. In particular, we analyse what happens when changing, first, the money transaction costs, and then the parameters relative to the open market operations.

\subsubsection{The role of money transaction costs}

Figure 4 shows the impulse response functions of a technology shock for different values of the transaction costs parameters, while simulated moments are reported in Table 5 . It is worth remembering that, in this framework, variations in the transaction costs reflect variations in the liquidity of the asset: the higher the transaction costs, the higher the liquidity premium associated with that kind of asset. It is evident from Figure 4 that the responsiveness of each yield increases when its own transaction cost increases. Table 5 shows that even yield volatility is larger, when the value of the transaction costs is higher. The intuition is simple. When transaction cost is lower (higher), the bond becomes more (less) liquid, and, therefore, the propensity of agents to reallocate income between money and bonds is higher (lower), since the degree of substitutability between money and bonds increases (decreases). As a result, the responsiveness to shocks of the bond's price and yield decreases (increases), as shocks can be better absorbed in liquid markets (i.e. the stress over yields is lower in liquid markets). Finally, a lower (higher) responsiveness of yields reflects, in turn, a lower (higher) degree of volatility of the simulated yields. In other words, deviations of prices and yields from the steady-state are less pronounced in a liquid market, in which it is relatively easy to trade asset. The price impact to a specific shock is lower.

\subsubsection{The role of open market operations}

Impulse response functions to a productivity shock and the moments of the simulated variables when varying the parameters of the open market operations $\eta_{\imath}$, for $\imath=S, M, L$, 
are respectively displayed in Figure 5 and Table 6 . They indicate that the higher the parameter of Open Market Operation for a specific bond, the lower is the responsiveness and the volatility of its own yield. The explanation is straightforward. The higher (lower) is the parameter, the lower (higher) is the quantity of bonds of that type that the central bank is buying or selling on the markets after a variation of the money demand. As a result, also the volatility of prices and yields of that specific asset turns out to be lower (higher). Also in this case, the feedback effects are not fully appreciable.

Lastly, it is worth briefly emphasizing the potentialities of this model of analyzing unconventional tools for monetary policy, such as Quanitative Easing policies, which have become very popular in the recent years, given that in many countries short-term interest rates have been very close to the zero lower bound. ${ }^{7}$ Indeed, within this framework, it would be possible to study the response of yields of different maturities to longer-term assets purchases by the central bank. This issue goes beyond the scope of the present paper, and is the focus of a work in progress. ${ }^{8}$

\subsection{Yield spread decomposition}

We decompose the yield spread into an expectations component and a term premium, in order to analyse the relative contribution of each component to movements of the yield spread. This decomposition takes the following form:

$$
\underbrace{R_{L, t}-R_{S, t}}_{\text {Yield spread }}=\underbrace{\left[\frac{1}{N} \sum_{j=0}^{N-1} E_{t} R_{S, t+j}-R_{S, t}\right]}_{\text {Expectations component }}+\underbrace{\left[R_{L, t}-\frac{1}{N} \sum_{j=0}^{N-1} E_{t} R_{S, t+j}\right]}_{\text {Term premium }}
$$

with $N=40$. Figure 6 displays the relative contribution of each component concurring to determine yield spread variations, using simulated data. From our results, as proved analytically in previous sections, the model generates substantial deviations from the EH. In fact, with baseline calibration, the expectations-related component accounts on average for more than $54 \%$ of yield spread changes (Figure 6). By increasing transaction costs on long-term bonds, the contribution of the term premium becomes predominant. At the contrary, an increase in transaction costs on short-term bonds leads the expectations component to take a larger share, since the wedge between short-term and long-term rate becomes smaller. ${ }^{9}$

\footnotetext{
${ }^{7}$ See, for example, Gagnon et al. (2010) and Krishnamurthy and Vissing-Jorgensen (2011).

${ }^{8}$ Falagiarda (2012).

${ }^{9}$ The graphs are available upon request.
} 


\section{Results from the estimated model}

Once the model has proved to do a good job in its calibrated version, in terms of both term structure moments and macro dynamics, a natural step forward is to carry out a more direct link of theory with data by explicitly estimating the model. The estimation is conducted on US data at a quarterly frequency over the period considered before (1987:32011:3).

The goal of the estimation exercise is twofold. First, we check whether the assumptions about the parameters used in the calibrated version are empirically plausible, at least as a first approximation. Obviously, our main focus is on parameters concerning money transaction costs and open market operations. Second, time series of the estimated term premium are compared with results obtained by Kim and Wright (2005), who use an affine term structure model to estimate term premium movements.

\subsection{The estimation technique}

Estimation is performed using Bayesian techniques, which have become very popular in the DSGE literature in the last decade, as carefully explained in Fernández-Villaverde (2010). Once the model has been log-linearized, we can write it in a state space representation, where the transition equation is:

$$
S_{t}=f\left(S_{t-1}, W_{t} ; \Theta\right)
$$

where $S_{t}$ is the vector of states, $W_{t}$ is the vector of innovations, and $\Theta$ is the vector of structural parameters.

Measurement equation is:

$$
Y_{t}=g\left(Y_{t-1}, Z_{t} ; \Theta\right)
$$

where $Y_{t}$ are the observables and $Z_{t}$ the measurement errors to the observables.

Given our data $Y^{T} \equiv\left\{Y_{t}\right\}_{t=1}^{T}$, the general expression of the likelihood function of the model is:

$$
\mathcal{L}\left(\Theta \mid Y^{T}\right)=\prod_{t=1}^{T} p\left(Y_{t} \mid Y^{T-1}, \Theta\right)
$$

The likelihood function is evaluated through the Kalman filter. ${ }^{10}$ According to Bayes' theorem, the posterior distribution of the parameters is given by:

$$
\pi\left(\Theta \mid Y^{T}\right)=\frac{p\left(Y^{T} \mid \Theta\right) \pi(\Theta)}{\int p\left(Y^{T} \mid \Theta\right) \pi(\Theta) d \Theta}
$$

Using a Random Walk Metropolis-Hastings algorithm, as described by Chib and Green-

\footnotetext{
${ }^{10}$ For more details, see Canova (2007).
} 
berg (1995), An and Schorfheide (2007), and Fernández-Villaverde (2010), we obtain an empirical approximation of the posterior density function of the model, ready to perform inference.

The chosen observables are output, inflation, consumption, money, short term rate, medium-term rate, and long-term rate. Quarterly data on real GDP, GDP deflator, real consumption expenditure, money base M0, and yields (respectively, 3-month, 1-year, and 10-year yields - constant-maturity interest rates, in percent per year) covering the period 1987:3-2011:3 are employed. They are obtained from the Federal Reserve Economic Data database. We calculate log-differences of each series, with the exception of interest rates. The dataset is then detrended using a linear trend.

\subsection{Prior distribution of the parameters}

Some parameters are not going to be estimated, since they are either obtained through the steady-state solution, or usually treated as fixed in the literature (such as the coefficient of intertemporal substitution $\beta$ ). The remaining parameters are estimated, and their prior distribution is shown in the second column of Table 7 , chosen consistently with the calibration of previous section, or following Zagaglia (2011) and other contributions in the literature.

\subsection{The results}

The posterior mean estimates of parameters are reported in the third column of Table $7 .^{11}$ The estimated posterior mean of almost all the parameters estimates is quite close to the prior mean, with the exception of the standard error and the stochastic process of government spending shock, which displays a higher standard error, and a lower persistence. Other divergences between priors and posteriors are physiological, as documented in the literature.

Looking at the estimates of free parameters - those regarding money adjustment costs and open market operations - it turns out that the mean of the posterior distribution is generally close to the mean of the prior assumptions, and, in any case, the estimates generally respect the ordering of their calibrated value, except for the parameter of medium-term bonds adjustment costs, slightly higher than that of long-term bond. Moreover, the estimates confirm that OMOs are more skewed towards short and medium-term securities. These results seem to provide a strong empirical support to our previous calibration and to the whole theoretical framework.

On the other hand, the main goal of the estimation carried out in this section is to show how powerful is the present model for studying term premium dynamics. We showed that this model is able to generate an endogenous term premium. Figure 7 compares the

\footnotetext{
${ }^{11}$ Estimates are obtained using two blocks of 100,000 replications each, of which the first 45 percent have been discarded. The convergence diagnostic tests indicate that the Markov chains converge. Moreover, the Bayesian IRFs reflect the dynamics highlighted in the calibrated model. For reasons of space, both set of graphs have not been reported here, but are available upon request.
} 
series of the estimated term premium with that obtained by Kim and Wright (2005), who employ an affine term structure model. It should be remembered that we are dealing with deviations from the steady-state and our time series have already been detrended: to facilitate comparisons, time series of variables of Kim and Wright (2005) have been detrended. From Figure 7 we observe a considerable similarity in the volatility of the two series. Secondly, the two term premia follow very similar patterns, as proved by the high correlation coefficient between them, given by 0.638 .

As a last exercise, we carry out the estimation over two sub-periods, 1987:3-1998:1 and 1998:2-2011:3. Figure 8 and 9 report posterior impulse response functions of term structure variables to technology and monetary policy shocks over the full sample period and the two sub-periods. ${ }^{12}$ They represent the mean of a series of IRFs obtained by drawing from the parameter posteriors. The responses have been rescaled in order to capture a $1 \%$ shock. First of all, it should be noted that the direction of the responses are consistent with the predictions obtained from the theoretical model. More importantly, it is possible to observe that the two sub-periods are characterized by different degrees of responsiveness of yields of different maturity. In fact, during the first sub-period, yields' reaction to shocks is smaller and less persistent in comparison with that relative to the second sub-period. The reason is likely to be found in the fact that in the recent years financial markets have been substantially more turbulent. The bubbles characterizing the early 2000s and the recent Great Recession are just the most known examples. Moreover, the pattern of the model relatively to the more recent sample period (1998:2-2011:3) shows a clear effect of the more active role of central banks over longer maturities, if compared with previous periods.

In conclusion, through this estimation exercise, we have shown that this approach, by considering the term premium as an endogenous variable, allows to analyze yield curve dynamics in a much deeper way than standard DSGE models. In particular, the estimated term premium is realistically large and follows very closely the pattern of that estimated by Kim and Wright (2005) using a finance model.

\section{Concluding remarks}

In this paper, we introduce a new way of modelling the term structure within a DSGE framework. In particular, by introducing portfolio adjustment frictions on bond trading, it is possible to generate segmented financial markets, where assets of different maturities are imperfect substitutes, to allow for a full endogeneization of a time-varying term premium.

The calibrated model is able to match both US term structure moments over the period 1987:3-2011:3 and the macro dynamics. Moreover, it generates a sufficiently large term premium, which reacts to shocks consistently with what found in previous studies, without using higher order approximations.

\footnotetext{
${ }^{12}$ The confidence intervals have not been reported for the sake of clarity. All the responses are nevertheless statistically significant at least at $5 \%$ level.
} 
The estimation exercise performed in Section 4 provides a strong empirical support to this theoretical framework. In particular, the estimates of the free parameters of the model are in line with their calibrated values, and the responses of yields of different maturity consistent with theoretical predictions. Moreover, the estimated term premium generated by the model is very similar to that obtained by Kim and Wright (2005), both in terms of pattern and volatility.

All in all, the most important contribution of this paper is to provide a new setting, through which the term premium can be incorporated into a microfounded macro framework with optimizing agents. Further work is needed to better evaluate the role of money, and to identify movements and determinants of the yield curve. In addition, the model proposed in this paper points to further avenues for future research, such as the introduction of financial intermediaries and different types of private assets, the analysis of the strategic asset allocation implications of this framework, and the adoption of a more effective feedback mechanism from the term structure to the macroeconomy, such that employed by Harrison (2012), where aggregate demand depends directly on interest rates of bonds of different maturities. Moreover, it would be interesting to adapt and use this framework to study the recent waves of Quantitative Easing policies carried out by central banks in the US and the UK. 


\section{Appendix. The steady-state}

$$
\begin{aligned}
& \lambda=(1-\beta \gamma)[C(1-\gamma)]^{-\frac{1}{\sigma}} \\
& \beta=\frac{\pi}{R} \\
& m^{-\chi}=\lambda\left(1-\frac{1}{R}\right) \\
& \Psi=\frac{\lambda}{L^{1 / \psi} w} \\
& \beta \frac{1}{\pi R}+\beta \phi_{i} \frac{1}{R_{i}} Y=\frac{1}{R_{i}}\left[1+\frac{3}{2} \phi_{i} Y\right] \\
& \phi_{i}=\frac{\frac{\beta R_{i}}{\pi R}-1}{Y\left(\frac{3}{2}-\beta\right)} \\
& \frac{G}{Y}=1-\frac{C}{Y}-I_{t}\left(1+A C_{t}^{I}\right)-\frac{\phi_{S}}{2} \frac{b_{S}}{R_{S}}-\frac{\phi_{M}}{2} \frac{b_{M}}{R_{M}}-\frac{\phi_{L}}{2} \frac{b_{L}}{R_{L}} \\
& w=(1-\alpha)\left(\frac{Y+\Phi}{L}\right)\left(1-\frac{1}{e^{Y}}\right) \\
& q=\alpha\left(\frac{Y+\Phi}{K}\right)\left(1-\frac{1}{e^{Y}}\right) \\
& \Phi=\left[1-\alpha\left(1-\frac{1}{\theta}\right)\right] A K^{\alpha} L^{1-\alpha} \Longrightarrow \frac{\Phi}{Y+\Phi}=\left[1-\alpha\left(1-\frac{1}{\theta}\right)\right] \\
& e^{Y}=\theta
\end{aligned}
$$

Combining equations (17) and (18), we have the following formula, from which we can derive $\phi_{K}$ :

$\beta E_{t} \frac{\lambda_{t+1}}{\lambda_{t}}\left\{(1-\delta)\left[1+\frac{3}{2} \phi_{K}\left(\frac{I_{t+1}}{K_{t+1}}\right)^{2}\right]+Q_{t+1}+\phi_{K}\left(\frac{I_{t+1}}{K_{t+1}}\right)^{3}\right\}=1+\frac{3}{2} \phi_{K}\left(\frac{I_{t}}{K_{t}}\right)^{2}$ 


\section{References}

Altig, D., Christiano, L. J., Eichenbaum, M., and Lind, J. (2011). Firm-specific capital, nominal rigidities and the business cycle. Review of Economic Dynamics, 14(2):225-247.

An, S. and Schorfheide, F. (2007). Bayesian analysis of DSGE models. Econometric Reviews, 26(2-4):113-172.

Andrés, J., López-Salido, J. D., and Nelson, E. (2004). Tobin's imperfect asset substitution in optimizing general equilibrium. Journal of Money, Credit and Banking, 36(4):665690.

Ang, A. and Piazzesi, M. (2003). A no-arbitrage vector autoregression of term structure dynamics with macroeconomic and latent variables. Journal of Monetary Economics, 50(4):745-787.

Barro, R. J. and Ursua, J. F. (2011). Rare macroeconomic disasters. Working Paper 17328, National Bureau of Economic Research.

Bekaert, G., Cho, S., and Moreno, A. (2010). New keynesian macroeconomics and the term structure. Journal of Money, Credit and Banking, 42(1):33-62.

Campbell, J. Y. and Cochrane, J. H. (1999). By force of habit: A consumption-based explanation of aggregate stock market behavior. Journal of Political Economy, 107(2):205251.

Canova, F. (2007). Methods for applied macroeconomic research. Princeton University Press.

Chib, S. and Greenberg, E. (1995). Understanding the Metropolis-Hastings algorithm. The American Statistician, 49(4):pp. 327-335.

Christiano, L. J. and Eichenbaum, M. (1992). Current real-business-cycle theories and aggregate labor-market fluctuations. American Economic Review, 82(3):430-450.

Christiano, L. J., Eichenbaum, M., and Evans, C. L. (2005). Nominal rigidities and the dynamic effects of a shock to monetary policy. Journal of Political Economy, 119(1):145 .

De Graeve, F., Dossche, M., Emiris, M., Sneessens, H., and Wouters, R. (2010). Risk premiums and macroeconomic dynamics in a heterogeneous agent model. Journal of Economic Dynamics and Control, 34(9):1680-1699.

Dewachter, H. and Lyrio, M. (2006). Macro factors and the term structure of interest rates. Journal of Money, Credit and Banking, 38(1):119-140.

Diebold, F. X., Piazzesi, M., and Rudebusch, G. D. (2005). Modeling bond yields in finance and macroeconomics. The American Economic Review, 95(2):415-420. 
Diebold, F. X., Rudebusch, G. D., and Aruoba, S. B. (2006). The macroeconomy and the yield curve: a dynamic latent factor approach. Journal of Econometrics, 131(1-2):309338.

Dixit, A. K. and Stiglitz, J. E. (1977). Monopolistic competition and optimum product diversity. American Economic Review, 67(3):297-308.

Epstein, L. G. and Zin, S. E. (1989). Substitution, risk aversion, and the temporal behavior of consumption and asset returns: A theoretical framework. Econometrica, 57(4):937969.

Evans, C. L. and Marshall, D. A. (2007). Economic determinants of the nominal treasury yield curve. Journal of Monetary Economics, 54(7):1986-2003.

Falagiarda, M. (2012). Evaluating Quantitative Easing: a DSGE approach. Unpublished manuscript.

Fernández-Villaverde, J. (2010). The econometrics of DSGE models. SERIEs: Journal of the Spanish Economic Association, 1:3-49.

Gagnon, J., Raskin, M., Remache, J., and Sack, B. (2010). Large-scale asset purchases by the Federal Reserve: Did they work? Staff Reports 441, Federal Reserve Bank of New York.

Gourio, F. (2009). Disasters risk and business cycles. Working Paper 15399, National Bureau of Economic Research.

Guvenen, F. (2009). A parsimonious macroeconomic model for asset pricing. Econometrica, 77(6):1711-1750.

Harrison, R. (2012). Asset purchase policy at the effective lower bound for interest rates. Bank of England working papers 444, Bank of England.

Hördahl, P., Tristani, O., and Vestin, D. (2006). A joint econometric model of macroeconomic and term-structure dynamics. Journal of Econometrics, 131(1-2):405 - 444.

Hördahl, P., Tristani, O., and Vestin, D. (2008). The yield curve and macroeconomic dynamics. Economic Journal, 118(533):1937-1970.

Hsu, A. (2011). Does fiscal policy uncertainty matter for bond risk premia? Unpublished manuscript.

Ireland, P. N. (2004). Money's role in the monetary business cycle. Journal of Money, Credit and Banking, 36(6):969-83.

Kim, D. H. and Wright, J. H. (2005). An arbitrage-free three-factor term structure model and the recent behavior of long-term yields and distant-horizon forward rates. Finance 
and Economics Discussion Series 2005-33, Board of Governors of the Federal Reserve System (U.S.).

Kim, J. (2000). Constructing and estimating a realistic optimizing model of monetary policy. Journal of Monetary Economics, 45(2):329-359.

Kozicki, S. and Tinsley, P. A. (2001). Shifting endpoints in the term structure of interest rates. Journal of Monetary Economics, 47(3):613-652.

Krishnamurthy, A. and Vissing-Jorgensen, A. (2011). The Effects of Quantitative Easing on Interest Rates: Channels and Implications for Policy. NBER Working Papers 17555, National Bureau of Economic Research.

Leeper, E. M. (1991). Equilibria under active and passive monetary and fiscal policies. Journal of Monetary Economics, 27(1):129-147.

Ljungqvist, L. and Sargent, T. (2004). Recursive macroeconomic theory. MIT Press.

Marzo, M., Söderström, U., and Zagaglia, P. (2008). The term structure of interest rates and the monetary transmission mechanism. Unpublished manuscript.

Marzo, M. and Zagaglia, P. (2011). Equilibrium selection in a cashless economy with transaction frictions in the bond market. MPRA Paper 31680, University Library of Munich, Germany.

Mehra, R. and Prescott, E. C. (1985). The equity premium: A puzzle. Journal of Monetary Economics, 15(2):145-161.

Piazzesi, M. and Schneider, M. (2006). Equilibrium yield curves. NBER Working Papers 12609, National Bureau of Economic Research.

Ravenna, F. and Seppälä, J. (2006). Monetary policy and the term structure of interest rates. Unpublished manuscript.

Rotemberg, J. J. (1982). Monopolistic price adjustment and aggregate output. The Review of Economic Studies, 49(4):517-531.

Rudebusch, G. D. (2010). Macro-finance models of interest rates and the economy. The Manchester School, 78:25-52.

Rudebusch, G. D., Sack, B. P., and Swanson, E. T. (2007). Macroeconomic implications of changes in the term premium. Federal Reserve Bank of St. Louis Review, 89:241-269.

Rudebusch, G. D. and Swanson, E. T. (2008). Examining the bond premium puzzle with a DSGE model. Journal of Monetary Economics, 55(Supplement 1):S111 - S126.

Rudebusch, G. D. and Swanson, E. T. (2009). The bond premium in a DSGE model with long-run real and nominal risks. Manuscript, Federal Reserve Bank of San Francisco. 
Rudebusch, G. D. and Wu, T. (2007). Accounting for a shift in term structure behavior with no-arbitrage and macro-finance models. Journal of Money, Credit and Banking, $39(2-3): 395-422$.

Rudebusch, G. D. and Wu, T. (2008). A macro-finance model of the term structure, monetary policy and the economy. Economic Journal, 118(530):906-926.

Schmitt-Grohé, S. and Uribe, M. (2004). Optimal fiscal and monetary policy under imperfect competition. Journal of Macroeconomics, 26(2):183-209.

Smets, F. and Wouters, R. (2003). An estimated dynamic stochastic general equilibrium model of the Euro area. Journal of the European Economic Association, 1(5):1123-1175.

Smets, F. and Wouters, R. (2007). Shocks and frictions in us business cycles: A bayesian DSGE approach. American Economic Review, 97(3):586-606.

Taylor, J. B. (1993). Discretion versus policy rules in practice. Carnegie-Rochester Conference Series on Public Policy, 39:195-214.

Tobin, J. (1969). A general equilibrium approach to monetary theory. Journal of Money, Credit and Banking, 1(1):15-29.

Tobin, J. (1982). Money and finance in the macroeconomic process. Journal of Money, Credit and Banking, 14(2):171-204.

Uhlig, H. (2007). Explaining asset pricing with external habits and wage rigidities in a DSGE model. American Economic Review, 97(2):239-243.

van Binsbergen, J., Fernández-Villaverde, J., Koijen, R. S., and Rubio-Ramírez, J. F. (2010). The term structure of interest rates in a DSGE model with recursive preferences. Working Paper 15890, National Bureau of Economic Research.

Vayanos, D. and Vila, J.-L. (2009). A preferred-habitat model of the term structure of interest rates. Working Paper 15487, National Bureau of Economic Research.

Wu, T. (2006). Macro factors and the affine term structure of interest rates. Journal of Money, Credit, and Banking, 38(7):1847-1875.

Yang, J. (2008). Macroeconomic determinants of the term structure of corporate spreads. Working Paper 29, Bank of Canada.

Zagaglia, P. (2011). Forecasting long-term interest rates with a dynamic general equilibrium model of the Euro area: The role of the feedback. Working Paper Series 19-11, Rimini Centre for Economic Analysis. 


\section{Tables}

Table 1: Steady-state values of some variables

\begin{tabular}{clc}
\hline \hline Notation & \multicolumn{1}{c}{ Description } & SS values \\
\hline$Y$ & Output & 1 (norm.) \\
$C$ & Consumption-output ratio & 0.57 \\
$T / Y$ & Taxes-output ratio & 0.1972 \\
$L /(1-L)$ & Ratio of market to non-market activities & 0.3 \\
& Debt/GDP ratio & 0.45 \\
& Fraction of very short-term debt over total debt & 0.233 \\
& Fraction of short-term debt over total debt & 0.142 \\
& Fraction of medium-term debt over total debt & 0.334 \\
& Fraction of long-term debt over total debt & 0.240 \\
$R$ & Gross money-market rate & 1.01046 \\
$R_{S}$ & Gross short-term rate & 1.00963 \\
$R_{M}$ & Gross medium-term rate & 1.01070 \\
$R_{L}$ & Gross long-term rate & 1.01428 \\
\hline
\end{tabular}


Table 2: Benchmark calibration of the parameters

\begin{tabular}{|c|c|c|}
\hline Notation & Description & Benchmark values \\
\hline & Preferences and technology & \\
\hline$\alpha$ & Share of capital in the production function & 0.36 \\
\hline$\beta$ & Intertemporal discount factor & 0.9975 \\
\hline$\sigma$ & Elasticity of intertemporal substitution & 0.5 \\
\hline$x$ & Elasticity of money demand & 7 \\
\hline$\psi$ & Elasticity of labor supply & 1 \\
\hline$\gamma$ & Habit formation & 0.7 \\
\hline$\theta$ & Elasticity of substitution between varieties of goods & 6 \\
\hline$\phi_{P}$ & Price adjustment costs & 100 \\
\hline \multirow[t]{2}{*}{$\phi_{K}$} & Capital adjustment costs & 1143.9 \\
\hline & Fiscal and monetary policy & \\
\hline$\psi_{0}$ & Fiscal policy constant & 0.1972 \\
\hline$\psi_{1}$ & Fiscal policy response to $b$ & 0.3 \\
\hline$\psi_{2}$ & Fiscal policy response to longer-term debt & 0.3 \\
\hline$\alpha_{\pi}$ & Monetary policy response to inflation & 1.5 \\
\hline$\alpha_{Y}$ & Monetary policy response to output & 0 \\
\hline \multirow[t]{2}{*}{$\alpha_{R}$} & Monetary policy inertia & 0.7 \\
\hline & Money-bonds transaction costs & \\
\hline$v_{S}$ & Short-term bonds & 0.0030 \\
\hline$v_{M}$ & Medium-term bonds & 0.0040 \\
\hline \multirow[t]{2}{*}{$v_{L}$} & Long-term bonds & 0.0041 \\
\hline & OMOs parameters & \\
\hline$\eta_{S}$ & Short-term bonds & 2.5 \\
\hline$\eta_{M}$ & Medium-term bonds & 2.5 \\
\hline \multirow[t]{2}{*}{$\eta_{L}$} & Long-term bonds & 7 \\
\hline & Autoregressive parameters & \\
\hline$\phi_{A}$ & Technology shock & 0.95 \\
\hline$\phi_{G}$ & Government spending shock & 0.90 \\
\hline$\phi_{M}$ & Mark-up shock & 0.90 \\
\hline$\phi_{P R}$ & Preferences shock & 0.90 \\
\hline \multirow[t]{2}{*}{$\phi_{T}$} & Inflation targeting shock & 0.90 \\
\hline & Standard deviations & \\
\hline$\sigma_{A}$ & Technology shock & 0.01 \\
\hline$\sigma_{G}$ & Government spending shock & 0.012 \\
\hline$\sigma_{R}$ & Monetary policy shock & 0.005 \\
\hline$\sigma_{P R}$ & Preferences shock & 0.005 \\
\hline$\sigma_{M}$ & Mark-up shock & 0.005 \\
\hline$\sigma_{\pi}$ & Inflation targeting shock & 0.005 \\
\hline$\sigma_{B S}$ & ST bonds shock & 0.0005 \\
\hline$\sigma_{B M}$ & MT bonds shock & 0.0005 \\
\hline$\sigma_{B L}$ & LT bonds shock & 0.0005 \\
\hline
\end{tabular}


Table 3: U.S. term structure main statistics 1987:3-2011:3

\begin{tabular}{lcccccc}
\hline \hline & FFR & 3-month & 1-year & 5-year & 10 -year & Spread \\
\hline Standard deviation & 2.522 & 2.288 & 2.390 & 2.051 & 1.788 & 1.382 \\
Correlation with output gap & - & - & - & - & - & -0.656 \\
\hline
\end{tabular}

Note: Main moments of U.S. yields data: Federal funds rate (FFR), 3-month, 1-year, 5-year, and 10-year yields (constant-maturity interest rates, in percent per year). The spread is calculated as the difference between the 10-year yield and the FFR. Statistics computed using Federal Reserve Economic Data.

Table 4: Term structure moments in the benchmark calibration

\begin{tabular}{lcccccc}
\hline \hline & PR & ST & MT & LT & Spread & Term premium \\
\hline Standard deviation & 0.763 & 2.195 & 1.828 & 1.957 & 1.202 & 1.339 \\
Corr. with output gap & - & - & - & - & -0.615 & -0.326 \\
\hline
\end{tabular}

Table 5: Term structure moments when varying money transaction costs

\begin{tabular}{lcccccc}
\hline \hline & PR & ST & MT & LT & Spread & Term premium \\
\hline Benchmark values: & $v_{S}=0.0030, v_{M}=0.0040, v_{L}=0.0041$ & \\
Standard deviation & 0.763 & 2.195 & 1.828 & 1.957 & 1.202 & 1.339 \\
Corr. with output gap & - & - & - & - & -0.615 & -0.326 \\
\hline
\end{tabular}

Increase of the costs: $v_{S}=0.0060, v_{M}=0.0080, v_{L}=0.0081$

$\begin{array}{lcccccc}\text { Standard deviation } & 0.763 & 2.815 & 2.179 & 2.364 & 1.606 & 1.595 \\ \text { Corr. with output gap } & - & - & - & - & -0.616 & -0.306\end{array}$

$\begin{array}{llllllll}\text { Corr. with output gap } & - & - & - & - & - & -0.616 & -0.306\end{array}$

Reduction in the costs: $v_{S}=0.0015, v_{M}=0.0020, v_{L}=0.00205$

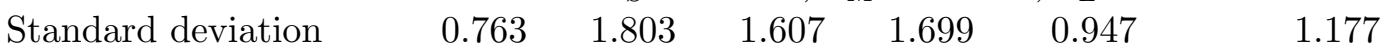

$\begin{array}{lllllllll}\text { Corr. with output gap } & - & - & - & - & -0.612 & -0.343\end{array}$

$\begin{array}{lllllll}\text { Standard deviation } & 0.763 & 1.340 & 1.346 & 1.391 & 0.647 & 0.987\end{array}$

$\begin{array}{llllllll}\text { Corr. with output gap } & - & - & - & - & - & -0.602 & -0.369\end{array}$ 
Table 6: Term structure moments when varying the parameters of OMOs

\begin{tabular}{|c|c|c|c|c|c|c|}
\hline & $\mathrm{PR}$ & ST & MT & LT & Spread & Term premium \\
\hline \multicolumn{7}{|c|}{ Benchmark values: $\eta_{S}=2.5, \eta_{M}=2.5, \eta_{L}=7$} \\
\hline Standard deviation & 0.763 & 2.195 & 1.828 & 1.957 & 1.202 & 1.339 \\
\hline Corr. with output gap & - & - & - & - & -0.615 & -0.326 \\
\hline \multicolumn{7}{|c|}{ Higher skeweness towards ST bonds: $\eta_{S}=1.5, \eta_{M}=9, \eta_{L}=15$} \\
\hline Standard deviation & 0.763 & 2.317 & 1.782 & 1.933 & 1.178 & 1.286 \\
\hline Corr. with output gap & - & - & - & - & -0.613 & -0.282 \\
\hline \multicolumn{7}{|c|}{ Higher skeweness towards LT bonds: $\eta_{S}=9, \eta_{M}=4, \eta_{L}=1.5$} \\
\hline Standard deviation & 0.763 & 2.071 & 1.799 & 2.148 & 1.399 & 1.547 \\
\hline Corr. with output gap & - & - & - & - & -0.623 & -0.407 \\
\hline
\end{tabular}


Table 7: Prior and posterior distribution (mean) of the parameters

\begin{tabular}{|c|c|c|c|}
\hline Notation & Description & Prior distribution & Posterior distr. \\
\hline & Preferences and technology & & \\
\hline$\sigma$ & Elasticity of intertemporal substitution & Normal $(1,0.5)$ & 1.151 \\
\hline$\chi$ & Elasticity of money demand & Normal $(7,3)$ & 5.706 \\
\hline$\psi$ & Elasticity of labor supply & Normal $(1,0.5)$ & 1.494 \\
\hline$\gamma$ & Habit formation & Beta $(0.7,0.3)$ & 0.403 \\
\hline$\phi_{P}$ & Price adjustment costs & Normal $(100,10)$ & 102.767 \\
\hline $\begin{array}{l}\alpha_{\pi} \\
\alpha_{Y} \\
\alpha_{R}\end{array}$ & $\begin{array}{l}\text { Monetary policy } \\
\text { Monetary policy response to inflation } \\
\text { Monetary policy response to output } \\
\text { Monetary policy inertia }\end{array}$ & $\begin{array}{l}\text { Normal }(1.5,0.9) \\
\text { Normal }(0.4,0.1) \\
\text { Beta }(0.5,0.2)\end{array}$ & $\begin{array}{l}2.197 \\
0.461 \\
0.875\end{array}$ \\
\hline $\begin{array}{c}v_{S} \\
v_{M} \\
v_{L}\end{array}$ & $\begin{array}{l}\text { Money-bonds transaction costs } \\
\text { Short-term bonds } \\
\text { Medium-term bonds } \\
\text { Long-term bonds }\end{array}$ & $\begin{array}{l}\text { Normal }(0.02,0.01) \\
\text { Normal }(0.02,0.01) \\
\text { Normal }(0.05,0.01)\end{array}$ & $\begin{array}{l}0.0074 \\
0.0166 \\
0.0100\end{array}$ \\
\hline $\begin{array}{c}\eta_{S} \\
\eta_{M} \\
\eta_{L}\end{array}$ & $\begin{array}{l}\text { OMOs parameters } \\
\text { Short-term bonds } \\
\text { Medium-term bonds } \\
\text { Long-term bonds }\end{array}$ & $\begin{array}{l}\text { Normal }(2.5,2) \\
\text { Normal }(2.5,2) \\
\text { Normal }(7,3)\end{array}$ & $\begin{array}{l}5.186 \\
4.191 \\
8.737\end{array}$ \\
\hline $\begin{array}{l}\phi_{A} \\
\phi_{G} \\
\phi_{M} \\
\phi_{T} \\
\phi_{P R}\end{array}$ & $\begin{array}{l}\text { Autoregressive parameters } \\
\text { Technology } \\
\text { Government spending } \\
\text { Mark-up shock } \\
\text { Inflation targeting shock } \\
\text { Preferences shock }\end{array}$ & $\begin{array}{l}\text { Beta }(0.85,0.1) \\
\text { Beta }(0.85,0.1) \\
\text { Beta }(0.85,0.1) \\
\text { Beta }(0.85,0.1) \\
\text { Beta }(0.85,0.1)\end{array}$ & $\begin{array}{l}0.750 \\
0.532 \\
0.840 \\
0.777 \\
0.386\end{array}$ \\
\hline$\sigma_{A}$ & $\begin{array}{l}\text { Standard deviations } \\
\text { Technology shock }\end{array}$ & Inv. Gamma $(0.4,2)$ & 0.335 \\
\hline$\sigma_{G}$ & Government spending shock & Inv. Gamma $(0.5,2)$ & 2.261 \\
\hline$\sigma_{R}$ & Monetary policy shock & Inv. Gamma $(0.4,2)$ & 0.051 \\
\hline$\sigma_{M}$ & Mark-up shock & Inv. Gamma $(0.4,2)$ & 0.271 \\
\hline$\sigma_{\pi}$ & Inflation targeting shock & Inv. Gamma $(0.1,2)$ & 0.057 \\
\hline$\sigma_{P R}$ & Preferences shock & Inv. Gamma $(0.4,2)$ & 0.399 \\
\hline$\sigma_{B S}$ & ST bond supply shock & Inv. Gamma $(0.4,2)$ & 0.982 \\
\hline$\sigma_{B M}$ & MT bond supply shock & Inv. Gamma $(0.4,2)$ & 1.034 \\
\hline$\sigma_{B L}$ & LT bond supply shock & Inv. Gamma $(0.4,2)$ & 0.921 \\
\hline
\end{tabular}




\section{Figures}

Figure 1: Impulse response functions of a positive technology shock
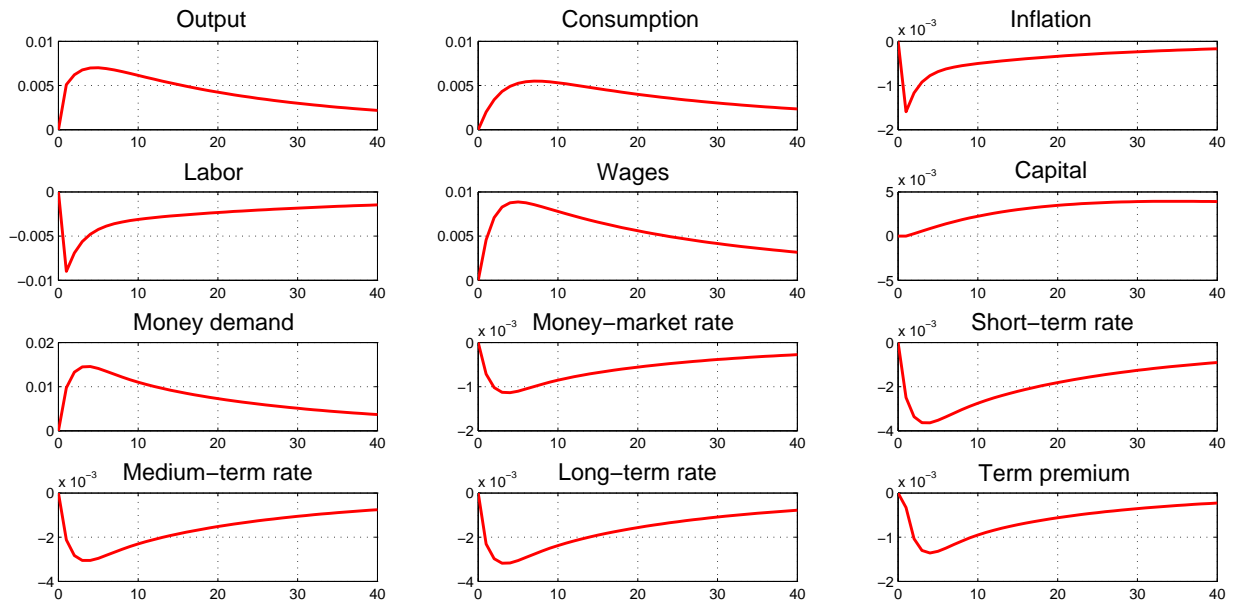

Figure 2: Impulse response functions of a contractionary monetary policy shock
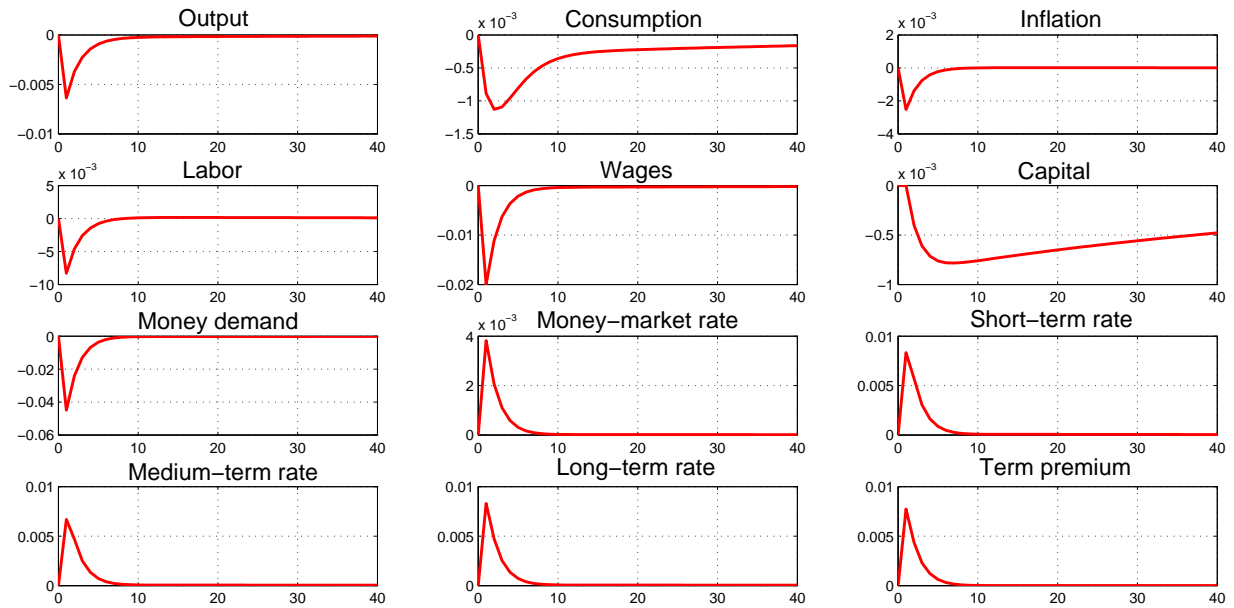
Figure 3: Impulse response functions of a government spending shock
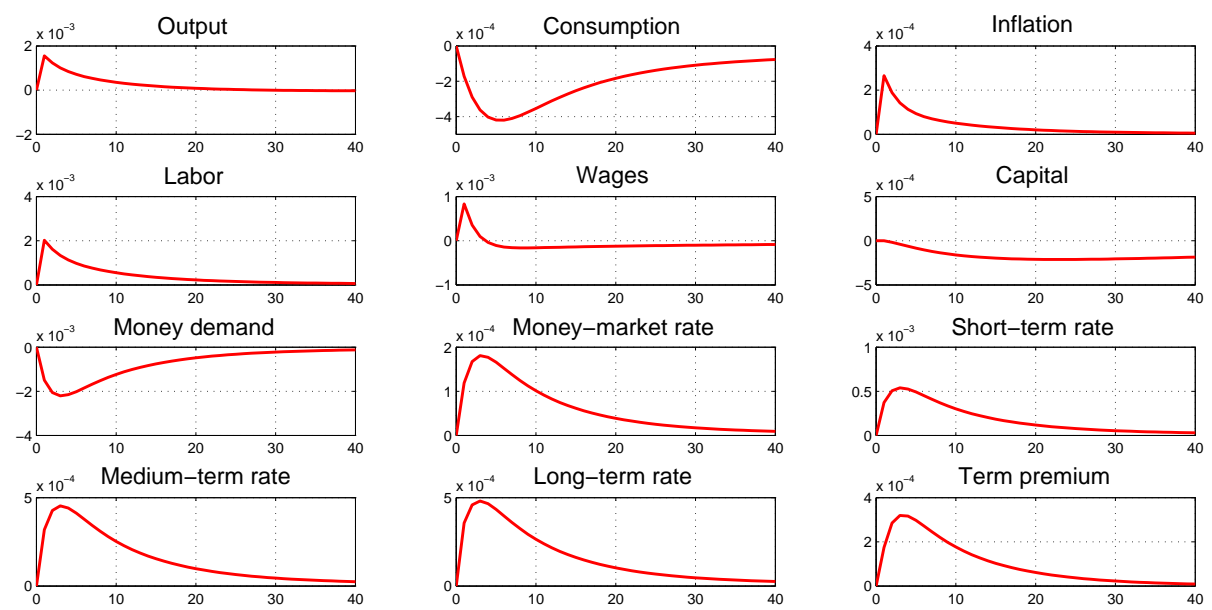

Figure 4: Impulse response functions of a positive technology shock when varying money transaction costs
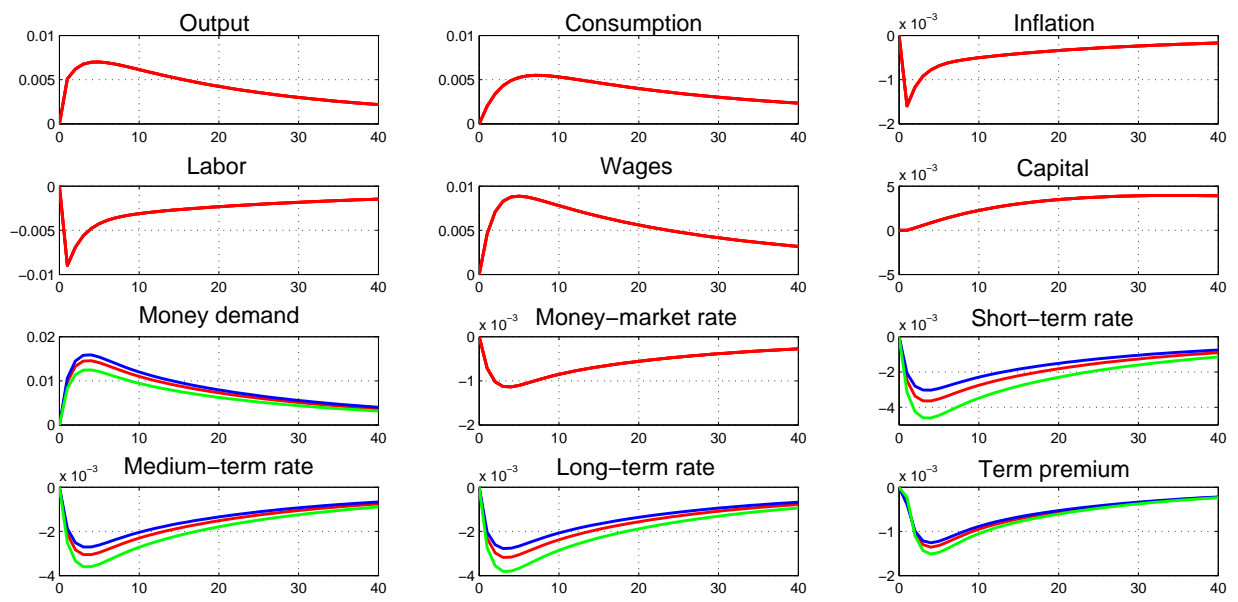

Benchmark values — $v_{S}=0.0015, v_{M}=0.0020, v_{L}=0.00205-v_{S}=0.0060, v_{M}=0.0080, v_{L}=0.0082$ 
Figure 5: Impulse response functions of a positive technology shock when varying the parameters of OMOs
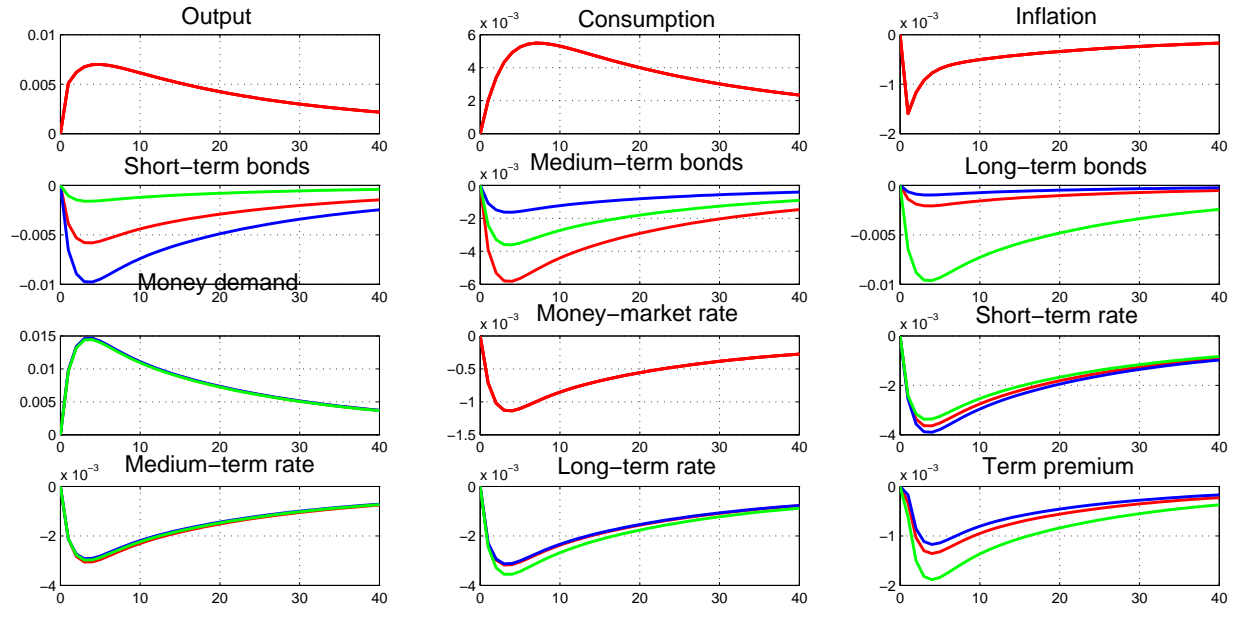

- Benchmark values — $\eta_{\mathrm{S}}=1.5, \eta_{\mathrm{M}}=9, \eta_{\mathrm{L}}=15-\eta_{\mathrm{S}}=9, \eta_{\mathrm{M}}=4, \eta_{\mathrm{L}}=1.5$

Figure 6: Decomposition of the yield spread - Benchmark case

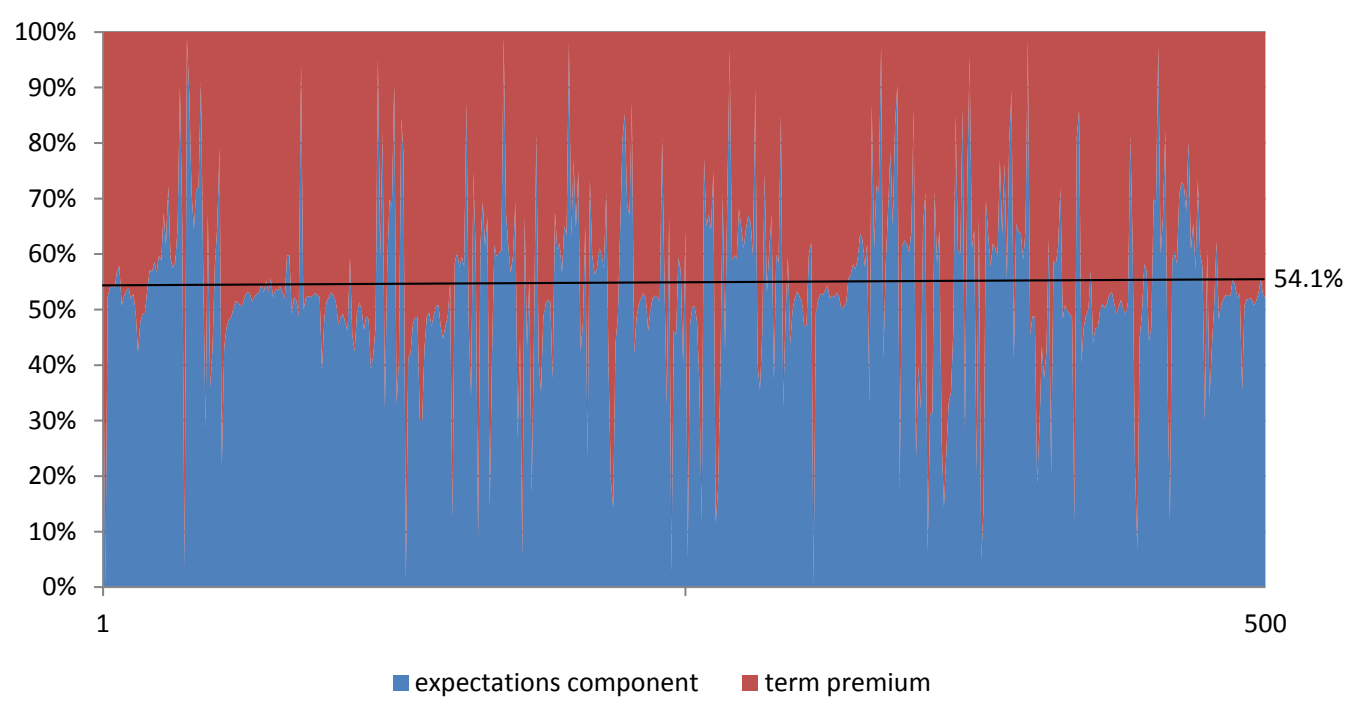


Figure 7: The estimated term premium vs. Kim and Wright's (2005) term premium 1990:4-2011:3

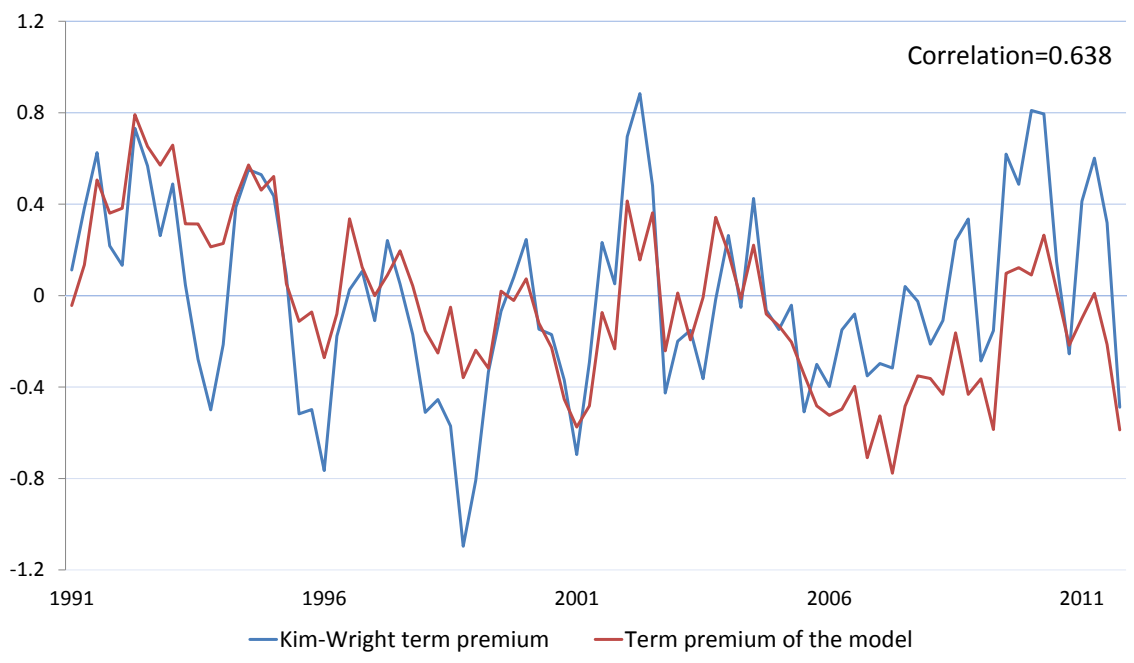

Figure 8: Posterior IRFs to a positive technology shock

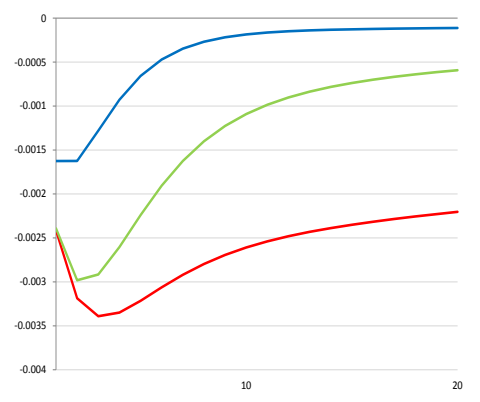

(a) Short-term rate

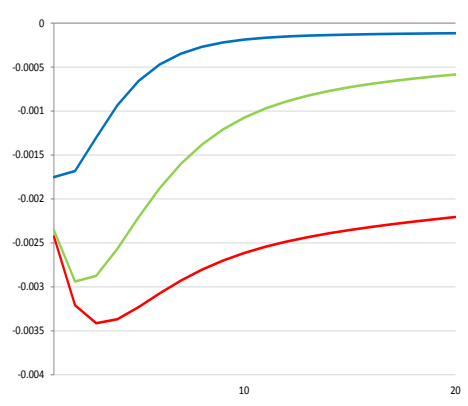

(b) Medium-term rate

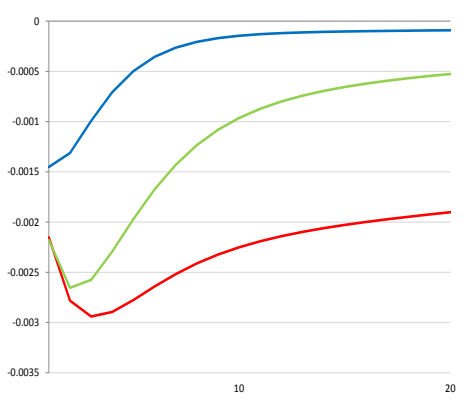

(c) Long-term rate

Notes: Red line: full sample period; Blue line: 1987:3-1998:1; Green line: 1998:2-2011:3.

Figure 9: Posterior IRFs to a contractionary monetary policy shock

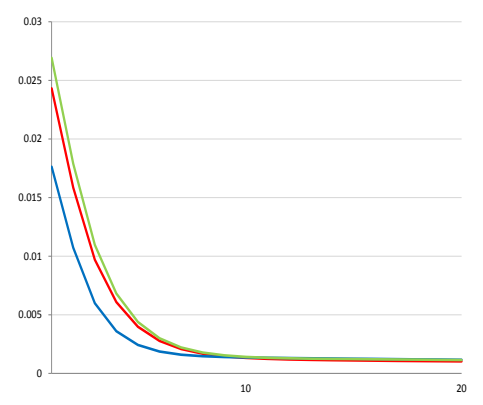

(a) Short-term rate

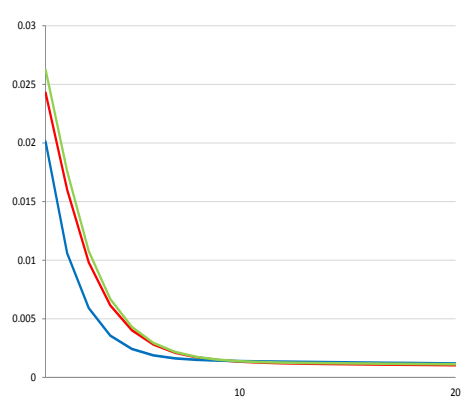

(b) Medium-term rate

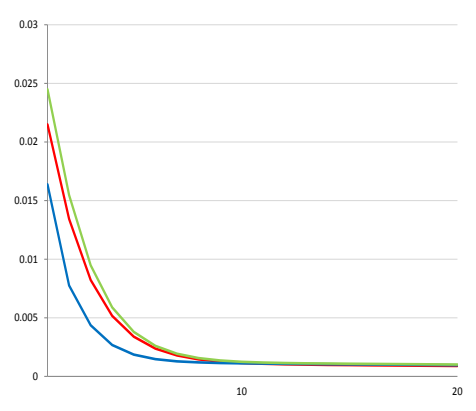

(c) Long-term rate

Notes: Red line: full sample period; Blue line: 1987:3-1998:1; Green line: 1998:2-2011:3. 


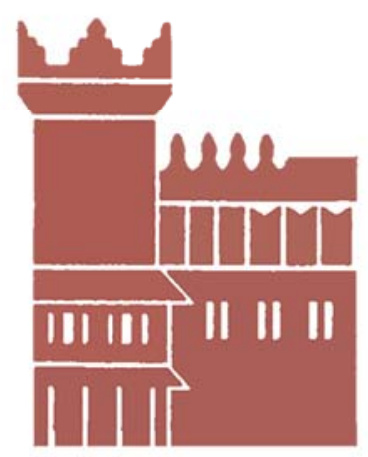

Alma Mater Studiorum - Università di Bologna DEPARTMENT OF ECONOMICS

Strada Maggiore 45

40125 Bologna - Italy

Tel. +39051 2092604

Fax +390512092664

http://www.dse.unibo.it 